\title{
IJTARP
}

International Journal of Transactional Analysis

\section{Psychological Boundaries and Psychological Bridges: A Categorisation and the Application of Transactional Analysis Concepts}

\author{
(C) 2018 Julie Hay
}

\begin{abstract}
Prompted by preparation of a presentation at a TA learning event, Part 1 of this paper provides a largely TA-based literature review of references to psychological boundaries, related to a proposed new framework for categorising such boundaries at the levels of person (intrapersonal, personal), people (interpersonal, family, neighbourhood), place (region, country, area, continent) and planet (environment, Earth, Universe). TA concepts seen as relevant for each boundary are described. Comments on practitioner boundaries lead into Part 2, which addresses psychological bridges across boundaries such as created through supervision and frameworks for increasing awareness of unconscious processes. A critique of the current TA field of application boundaries is included and Part 2 concludes with a model that represents a general bridge to contact.
\end{abstract}

\section{Key words}

transactional analysis, psychological boundaries, psychological bridges, script, childhood development, family dynamics, group imagoes, sailship success, power, transference, dual relationships, supervision, power, fields of application, TA competencies

\section{Introduction}

This paper began during preparation for a presentation at a multi-level learning event run by the South Asian TA Association in Bangalore in January 2018, where the assigned topic was Boundaries and Bridges. I conducted an initial literature review and developed a categorisation of boundaries into the levels of person, people, place and planet. Dialogue with the audience during the presentation, and a request by participants to provide a summary, prompted a more thorough literature review and the development of further ideas, particularly about psychological bridges. Part 1 of this paper focuses on boundaries and I indicate various TA concepts that seem to me to be relevant to a nested set of boundaries that apply to us all. Early in Part 1 I refer briefly to power, because of its significance in terms of maintaining or breaching boundaries. I conclude Part 1 with some comments on professional boundaries as a lead in to Part 2, where I consider various ways in which we can create bridges across boundaries. A significant element of this is through professional supervision, so I have continued the literature review to include material about stages and domains of supervision, the unconscious processes to which we need attend, and the implications of dual relationships. I continue with a critique of the way in which TA fields of application create additional boundaries and give ideas for how this might be overcome. I conclude Part 2 with an overview of a model for contact across boundaries generally.

As with the presentation in India, my intentions are:

1. to provide a contemporary model from which to consider how psychological boundaries relating to individuals, groups, and communities at various levels, and the internationally-determined professional boundaries that apply to TA fields of application, impact on our work as professionals;

2. to suggest how various TA concepts can be thought of as psychological bridges to contact, whether our clients are within the organisational, educational, counselling/coaching or psychotherapy fields of application;

3. to prompt thinking within the TA community about whether our competencies might be more usefully focused on being transactional analysts.

\section{Part 1: Boundaries}

\section{Some Initial Thoughts}

Edward Gurowitz (1975) proposed that we think of fences as what keep us in, and walls as what keep others out. 
Kaplan, Capace \& Clyde (1984) proposed that boundaries relate to self and walls relate to others.

Gurowitz also pointed out that boundaries can be physical or psychological. Most of what follows refers to psychological boundaries, fences and walls. We need to recognise, therefore, that we are constructing (Allen \& Allen, 1991) and co-creating them (Summers \& Tudor, 2000). Just as I will use a metaphor later to represent an organisation or any surrounding boundary, we are imagining that we have boundaries beyond the physical.

\section{Diagrams}

On the principle that TA makes maximum use of diagrams (one of Berne's legacies), here are some of the various ways in which boundaries are diagrammed within the TA literature. I identified three main formats, plus another from outside the TA literature:

A series of dots, variously referred to as lax, diffuse, weak or porous;

A solid line, called rigid, fixed, inflexible or firm - and where the last term sounds more healthy than the others;

A series of dashes, referred to as permeable, flexible or open and which we are presumably meant to regard as 'healthy.'

A series of dot-dash as a semipermeable boundary, named 'perforating' by non-TA author Lifshitz-Assaf (2017), which allows only inward movement.

To these we can add two more ideas from Muriel James (1986), that she related only to ego state boundaries but which we might apply more generally:

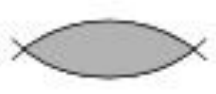

Two intersecting curves with a shaded overlap is the way in which we often show contaminations between ego states;

Lesions, or sore spots, which she showed by using dotted lines for part only of the boundary of an ego state.

Although James was referring to ego states, we could use the same formats to show the boundaries of groups, or they could be drawn vertically as the boundaries between ego states of different people, rather like Tony White (1997) suggested in an alternative diagram for symbiosis with Person $A$ and Person $B$ drawn with a dashed circle each that then join together to 'create' a Person $\mathrm{C}$ with two overlapping circles as shown in Figure 1.

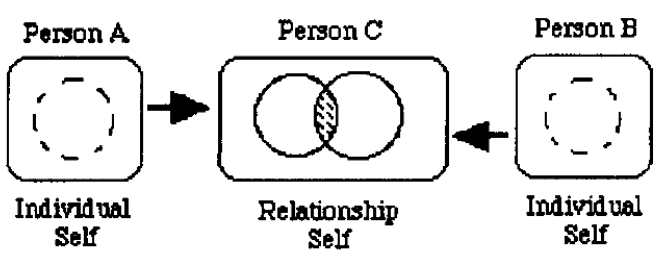

Figure 1: Attachment (White, 1997, p.301)

\section{Asymmetrical Boundaries}

Denton Roberts (1975) suggested that we have a nested set of boundaries, ranging from the personal to the cultural boundary. His original proposal was for personal, sexual, family, ethnic, provincial, social class, and cultural boundaries. Using a set of nested circles as boundaries, he described how a distortion in one boundary will trigger similar distortions in all further boundaries. He pointed out that injunctions would likely cause distortion in the personal level and hence impact on all levels; however, if the distortion is, for example, at the ethnic level then it needs to be treated at that level and not at the personal level where the problem may not apply.

Roberts included a sexual boundary about male/female (1975) whereas current thinking allows for many more options than this binary split that has so little biological basis. For many, even the extended range of options for those who are not cisgender (LGBT currently extended to lesbian, gay, bisexual, transgender, questioning, queer, intersex or any other term that may be used to indicate a gender identity that does not match the sex assigned at birth) will still result in a boundary distortion although, like religion or ethnicity, this distortion may occur within the family, village or wider social grouping.

\section{Boundary Categorisations}

A variation of Roberts' selection of boundaries is shown in Figure 2, albeit without any distortions. I have also grouped them into 4 'types' which I have labelled person, people, place and planet. In the rest of Part 1 of this paper, I give ideas and examples of TA concepts that may help us analyse what exists within or between the boundaries.

\section{Person}

- intrapersonal - ego states;

- $\quad$ personal - identity, growing up;

\section{People}

- interpersonal - interactions, behaviour;

- family - will determine ethnicity; may determine class, religion - later becomes our team/group at 
work or elsewhere, classroom, therapy group, etc;

- neighbourhood, street, village - may reinforce class, religion - later becomes our organisation, association, etc;

\section{Place}

- region (within a country) - may also determine religion;

- country - may equate to race;

- $\quad$ area within continent, may incorporate or override country (e.g. South Asia, West \& East Europe, Midwest USA);

- continent - although this may not be as significant as the area within the continent;

\section{Planet}

- environment (e.g. city, rural, mountains, desert, etc);

- Earth/the World;

- Universe - because President Trump has recently announced plans to go to the moon again (:) and astronomers are talking of planets which might support life.

\section{Power Potentials}

At the suggestion of a reviewer, I have added here some comments on power as this is a significant contributor to the appropriate and inappropriate maintenance of boundaries, whilst also being how boundaries may be breached when that option is chosen instead of building bridges. Power may reinforce or challenge boundaries within any of the categories I describe below.

Otto Altorfer (1977) contrasted formal courtesy with authentic courtesy, and formal power with personal power. He made the case [without references] for awareness and appropriate use of strokes and stroking patterns, and avoidance of discounting. $\mathrm{He}$ explained that authentic courtesy is needed to respond to the true feelings that may be hidden in the nonverbal messages, and that personal power "relies on mutuality and the principle of seeking agreement and consensus... [and needs that we] recognize needs for belonging, self-development, and self-actualization..." (p.341).

Krausz (1986) defined power as "the ability to influence the actions of others, individuals or groups." (p. 85). She then defined leadership as the way that power is used in that process of influencing. She went on to consider two sources of power: organisational power related to status within the structure, function in the system, and the extent of influence on others that the status assigns; and personal power as the specific characteristics, experiences, knowledge, expertise and ways of relating to others. She pointed out that
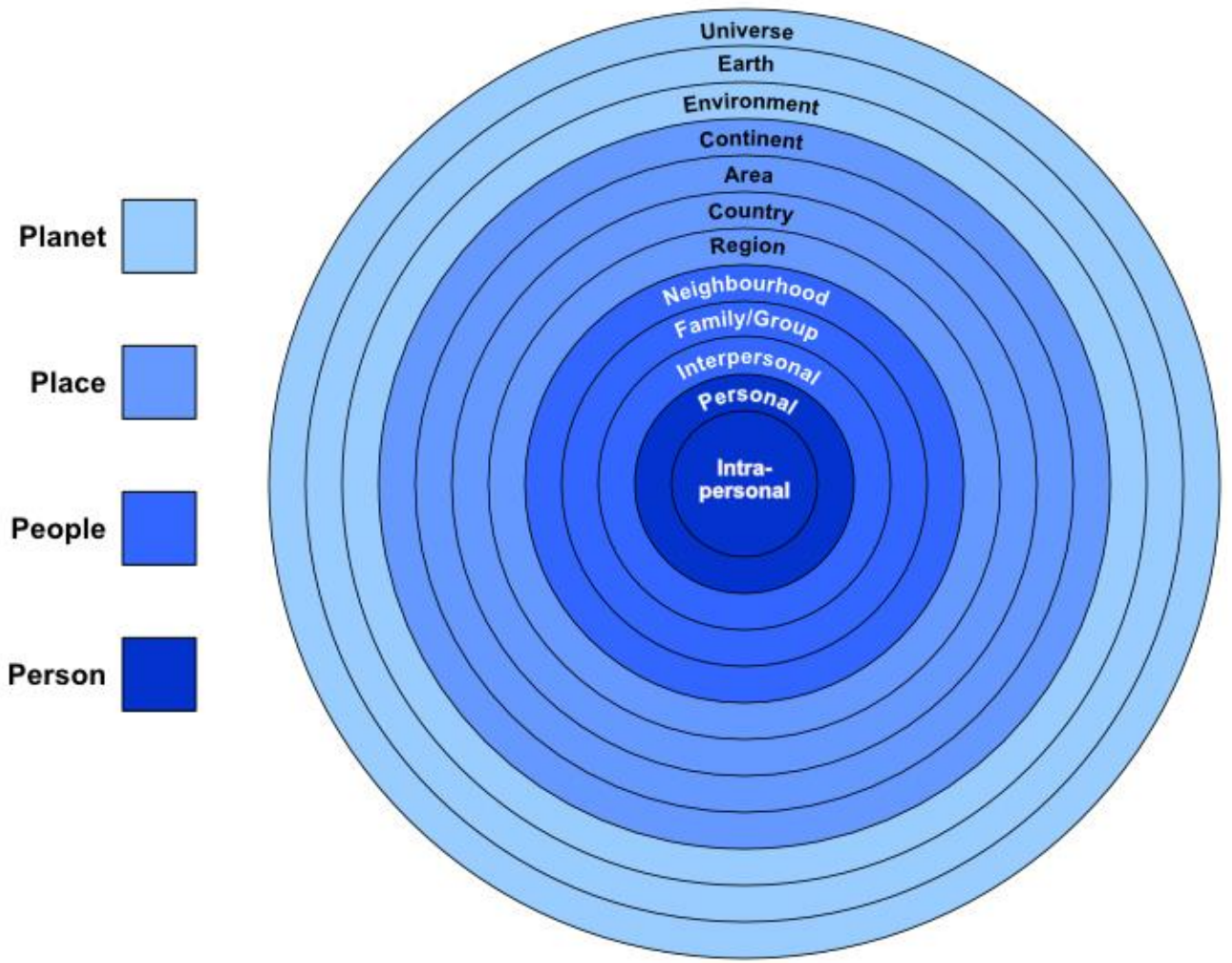

Figure 2: Boundaries 
organisational power is formally distributed between the members of an organisation whereas personal power is not distributable and depends on each individual. She also claimed that organisational power is activity oriented while personal power is results oriented, although she did not give any explanation for that.

Steiner (1987) commented in his Abstract that "Power is almost universally and mistakenly seen as the capacity to control other people". (p. 102). He proposed a more positive paradigm of power as the capacity to effect change and identified seven sources of power based on the ancient theory of the chakras of
Kundalini yoga. He referred to these as a rainbow of options rather than the unidimensional power based solely on control, commenting that each may be underdeveloped to the point of nonexistence or overdeveloped so that it crowds out other sources of power.

I (Hay, 2011a) have pulled together the various typologies of power to produce what I refer to as power potentials, meaning the sources of power. Table 1 shows also how I classify power sources mentioned by Krausz and Steiner. I regard coercion as a behaviour rather than a source of power.

\begin{tabular}{|c|c|c|}
\hline Hay 2015 & Krausz 1986 & Steiner 1987 \\
\hline $\begin{array}{c}\text { Physical - as in being stronger, } \\
\text { bigger, etc than others or using } \\
\text { supporters who have physical } \\
\text { power, such as gangsters, } \\
\text { mercenaries, etc }\end{array}$ & $\begin{array}{c}\text { Coercion/pressure - based on fear of punitive acts } \\
\text { and employed to ensure that individuals or groups } \\
\text { will comply. Leads to an organisational climate of } \\
\text { alienation }\end{array}$ & $\begin{array}{l}\text { Grounding - the capacity to } \\
\text { stand one's ground }\end{array}$ \\
\hline $\begin{array}{l}\text { Pecuniary (i.e. Financial) - having } \\
\text { control over tangible rewards } \\
\text { and penalties }\end{array}$ & $\begin{array}{l}\text { Reward - the capacity to assign direct or indirect, } \\
\text { material or psychological compensations such as } \\
\text { money, position, strokes, etc. Leads to an } \\
\text { organisational climate of insecurity }\end{array}$ & \\
\hline $\begin{array}{l}\text { Performance - being an expert, } \\
\text { having knowledge that others } \\
\text { lack }\end{array}$ & $\begin{array}{l}\text { Knowledge - related to skills, knowledge, and } \\
\text { experience relevant to the job and the organisation. } \\
\text { Leads to an organisational climate of acceptance, } \\
\text { security but also possibly dependence }\end{array}$ & $\begin{array}{l}\text { Knowledge - science, wisdom, } \\
\text { vision and intuition }\end{array}$ \\
\hline $\begin{array}{l}\text { Personal - interpersonal and } \\
\text { communication skills, emotional } \\
\text { intelligence }\end{array}$ & $\begin{array}{l}\text { Interpersonal Competence - based on } \\
\text { communication skills, empathy, authenticity, } \\
\text { respect, trust and capacity for intimacy. Leads to an } \\
\text { organisational climate of trust and openness }\end{array}$ & $\begin{array}{l}\text { Control - ability to aggressively } \\
\text { manipulate others and the } \\
\text { environment; } \\
\text { Communication - create in } \\
\text { others feelings and ideas that } \\
\text { reflect our own }\end{array}$ \\
\hline $\begin{array}{l}\text { Psychological - positively as } \\
\text { charisma or negatively through } \\
\text { ulterior transactions }\end{array}$ & $\begin{array}{l}\text { Support - based on the ability to stimulate the } \\
\text { involvement of peers, superiors, subordinates and } \\
\text { others. Leads to an organisational climate of anxiety }\end{array}$ & $\begin{array}{l}\text { Passion -power to create, } \\
\text { recreate, transform; } \\
\text { Love - to nurture, heal and } \\
\quad \text { instil hope; } \\
\text { Transcendence - appreciation } \\
\text { of unity with the Universe }\end{array}$ \\
\hline $\begin{array}{l}\text { Positional - the power that } \\
\text { comes with the role, the level } \\
\text { within the hierarchy, the legal } \\
\text { context }\end{array}$ & $\begin{array}{l}\text { Position - related to the status a person has in the } \\
\text { organisational structure and/or their job, this is also } \\
\text { known as institutional, legal, traditional or legitimate } \\
\text { power and theoretically those with equal status have } \\
\text { equal power. Leads to an organisational climate of } \\
\text { depression and confusion. }\end{array}$ & \\
\hline $\begin{array}{l}\text { Political - based on ideologies, } \\
\text { beliefs, values that others (can be } \\
\text { persuaded to) adopt }\end{array}$ & & \\
\hline
\end{tabular}

Table 1: Power Potentials (Hay, 2015) 


\section{Intrapersonal Boundaries}

Suggested TA concepts: script, transgenerational script, hot potato, cycles of development, spirals within spirals

\section{Script}

It is now generally accepted that we arrive in the world with a set of genes which may or may not be turned on by factors within our environment. We need to be cautious, therefore, in claiming that everything can be explained by transactional analysis concepts. However, with that caveat, there are still plenty of TA concepts that add considerably to our understanding of how nurture has impacted upon nature.

In terms of our intrapersonal boundaries, this can be thought of as how we create our own identity and therefore script is an obvious TA concept to consider. Figure 3 shows my (Hay, 2012) script matrix that incorporates Holloway's (1977) idea of showing the arrows stopping short, to emphasise the fact that the child makes an interpretation of the interactions from the parents, and hence makes a decision, albeit without the benefit of enough knowledge of the world. I (Hay, 1995, 2012) have extended this by using a dotted line for the arrows, as Berne (1966, p.172) did once for counterscript only. This is a reminder that the child makes decisions based on their perception of what is going on. Figure 4 shows Hay's (2012) Autonomy Matrix that demonstrates how most parents genuinely want to support their children.

\section{Transgenerational Script}

John James (1984) quoted Berne (1972) for the comment that "The most intricate part of script analysis in clinical practice is tracing back the influence of the grandparents." (p.288). He then added the story from James \& Jongeward (1971, p.97) about the bride cutting off the ends of the baked ham and then learning that grandmother had only done that because her pans had been too small. James goes on to refer to the 'family parade of scripts', adding that Berne had written that parents were not at fault because they were merely passing on what they had received from their parents and grandparents.

When considering the way in which transgenerational scripts (Noriega Gayol, 2002, 2004) may be passed on, Gloria Noriega (2009) presents an adaptation from Berne (1972) of a 'family parade', as shown in Figure 5 , commenting that "Script messages are transmitted by unconscious communication between the ego states of family members from one generation to the next. This process occurs from the P1 of mother or father to the P1 of the child. In this way, the transmission of script messages may run through several generations - going back to grandparents, great-grandparents, great-great-grandparents, and forwards to children, grandchildren, great-grandchildren, and beyond." (p. 9).

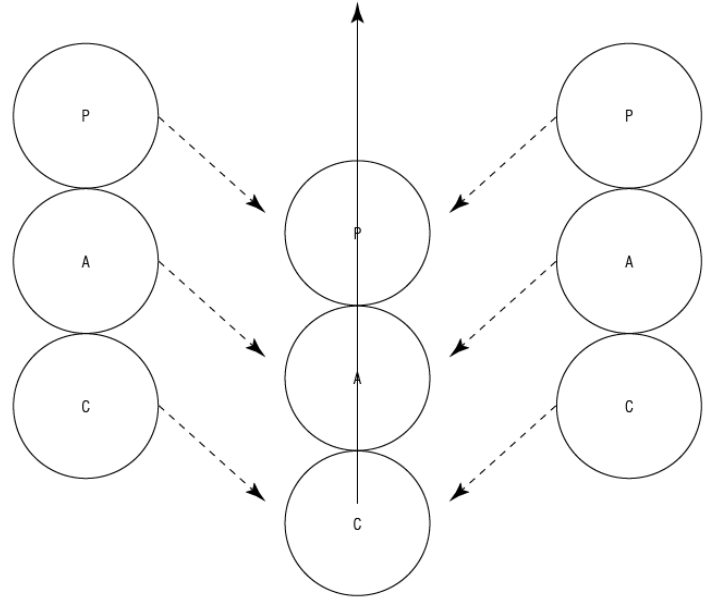

Figure 3: Script Matrix (Hay, 2012, p.18)

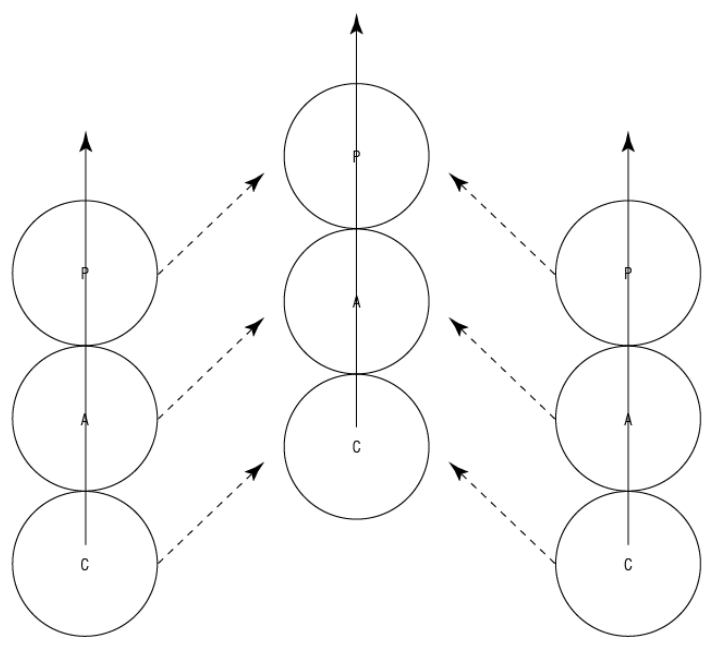

Figure 4: Autonomy Matrix (Hay, 2012, p.19)

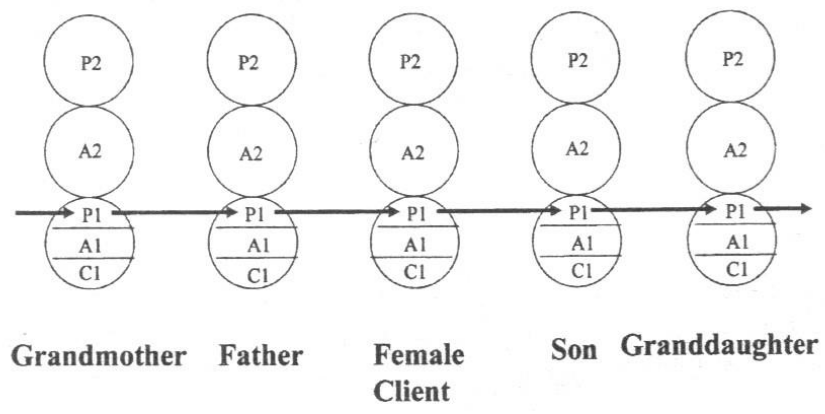

Figure 5: A Family Parade (adapted from Berne, 1972 p. 284) (Noriega, 2009 p. 9)

Writing about family constellation theory, McQuillin \& Welford (2013) link this approach to the hot potato (English 1969) and provide an example of a client who resolved her own issue of apparently wishing to go to a beach and die, and only later found out that her great-grandmother had in fact done this through getting hypothermia. They provide the diagram in Figure 6 to show how intergenerational impasses may be caused by the transition of a hot potato. 


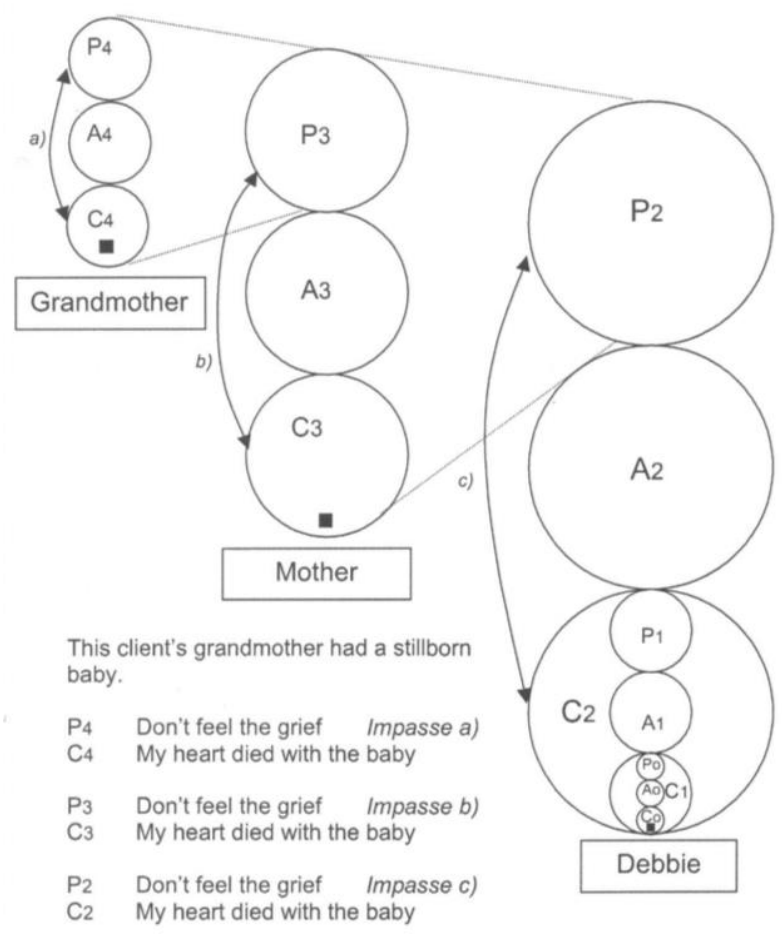

Figure 6: Intergenerational Impasses Caused by Transmission of a hot potato (McQuillin \& Welford, 2013 p. 360)

\section{Cycles of Development}

Levin (1982) identified seven stages in the human developmental process and, significantly, showed that these occur in cycles throughout our lives. In each stage of the initial cycle described by Levin, we have certain developmental tasks to complete and few of us are in circumstances where we can succeed totally. As we recycle through the equivalent period in later life, we have another opportunity for growth but we are also at risk of experiencing the same problems as occurred for us before. Unfortunately, we may well then repeat the same strategies that were unsuccessful for us previously.

She provided two diagrams to illustrate her conclusions. Figure 7 shows her diagram of the familiar three stacked circles to illustrate ego states, with the addition of a skin around them, and with the Child divided horizontally into three sections. She numbered these and explained that she chose to label them as: 1 - Natural Child, 2 - Little Professor, 3 Adult, 4 - Supernatural Child, 5 - Parent, 6 - the outer skin unifying the ego states, and $7-$ a repetition of the first six. She also explained that she had chosen the term Supernatural Child to avoid the pathological connotations of labels such as Witch Parent, and also to reflect the interest in magic that is characteristic of 4-6-year olds.

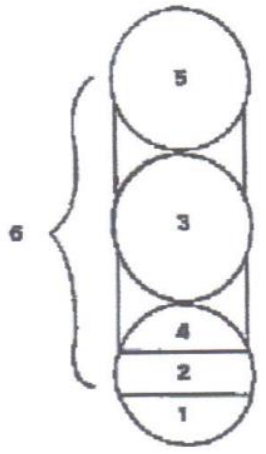

(Stage Seven is a repetition of the first six.)

Figure 7: Ego State Development (Levin 1982 p. 130)

Figure 8 show's Levin's diagram of the spiral showing major cycles and her labels for the different stages. In this, she marked an asterisk to show the end of adolescence, and a double asterisk to mark the end of the second major cycle, commenting that this is often known as a midlife crisis. Levin commented that "The significance of this developmental cycle is in its application, for we can use it to develop our power in all the phases of our lives. Individuals can understand the issues of personal growth and thus translate script limitations into options for effective action [Examples of use by couples, parents, teachers, patients, organisations, and therapists ]... Such a wide range of application is possible because the tides of every life in every time and place are connected to the cycle of development as essentially as the ocean tides are connected to the pull of the moon." (p. 138).

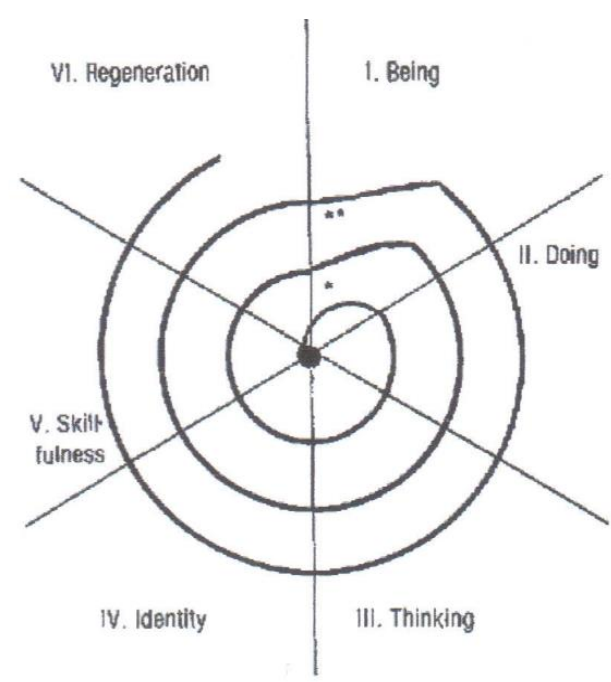

Figure 8: Major Phases (Levin 1982 p. 136) 
In Table 2, I reproduce a summary of the stages, indicating the name of the stage (with Exploring as my preferred alternative for Doing), the ages of the young person, the way that Levin names the ego states, and what the individual needs in order to complete their developmental tasks appropriately.

It may seem as if we have problems as grown-ups but are in fact replaying a childhood stage and unconsciously experiencing an opportunity to deal with unmet development needs.

\section{Spirals within Spirals}

In Hay (2009) I also noted that Levin had mentioned that, in addition to cycles timed according to our age, we also experience shorter periods triggered by specific events. I therefore introduced the notion of 'spirals within spirals' - Figure 9. These may span months and years but they might equally last for minutes and hours only. At any time in life, we will be experiencing a spiral that relates to the latest change that has occurred in our life, however small or large that may be, plus we will still be experiencing also the impact of the major lifetime spiral, and of any other spirals that may be in effect at the same time. Any problems will be multiplied when stages overlap in which we have 'unfinished business'. Fortunately, the same multiplier effect will occur for any stages in which we are particularly strong.

We can illustrate the spirals within spirals process by considering change that will happen to many of us at some time - starting a new job. This will generate its own spiral that will last for several weeks, or depending on the complexity of our work, months or even years:

1. We need time for a short interval for us to simply get used to being at our new place or work, during which we need to feel welcome.

2. We want time for exploring. We want to do this at our own pace. An important part of this exploration will be the opportunity to meet people and find out what they do.

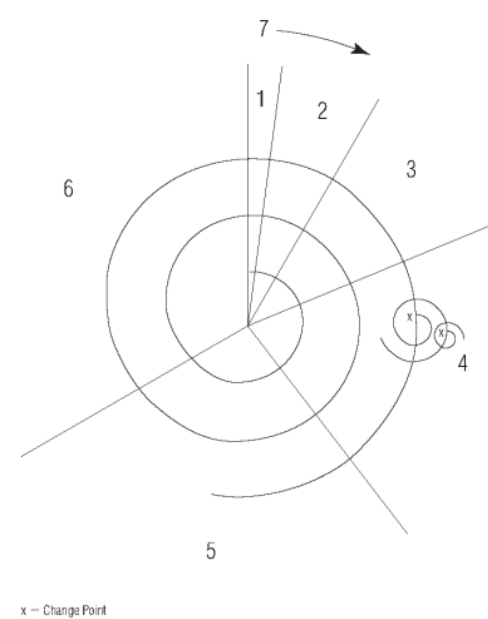

Figure 9: Spirals within Spirals (Hay, 2012, p.206) (Note that I draw the stages proportionally to represent the time spent in them rather than dividing them equally as Levin had done)

\begin{tabular}{|l|l|l|l|l|}
\hline Stage 1 & Being & $0-6$ months & Natural Child & nurturing \\
\hline Stage 2 & Doing (Exploring) & $6-18$ months & Little Professor & stimulation \\
\hline Stage 3 & Thinking & $1 \frac{1 / 2-3 \text { years }}{\text { Adult }}$ & test limits \\
\hline Stage 4 & Identity & $3-6$ years & Supernatural Child & test power \\
\hline Stage 5 & Skilful & $6-12$ years & Parent & own way \\
\hline Stage 6 & Regeneration & $12-18$ years & unifying & integration \\
\hline Stage 7 & Recycling & rest of life & repeat \& grow & relationships \\
\hline
\end{tabular}

Table 2: Stages of Development (Hay, 2011b, p.37) 
3. We now want to do our own thinking about the job. We need a manager who encourages us to do this, and then is willing to discuss our views.

4. We move into creating our own identity in the job. We need to believe that we have an element of choice over this.

5. We are now ready to learn the skills required to do the job. We need to have a good idea of the job itself, and our personal identity within it, if we are to make maximum use of training.

6. We want to integrate the previous stages. As we undertake the tasks of the job, we are pulling together our prior efforts of exploration, decision making and learning.

7. We begin the recycling stage. We have completed our transition into the new job. We will now move through each stage again but with far less impact. The effect of this particular spiral will fade. Soon, we will forget that we changed our job. We will function at our peak level until some other change comes along.

\section{Personal Boundaries}

Suggested TA concepts: ego state development, symbiosis - and see at the end of Part 1 for comments on professional boundaries, which will inevitably be impacted upon by, and impact upon, our personal boundaries.

Like Levin, Vincent Lenhardt (1991) also presented a model of childhood stages but with a focus on dependence, counterdependence, independence and interdependence. This is particularly useful when considering the development of personal boundaries, especially as he provided some diagrams to illustrate how an individual develops their 'full set of ego states'.

Originally presented at a conference, Lenhardt (2004) subsequently referenced his ideas to Symor (1983). The material below is an adaptation based on notes taken and diagrams noted by me in 1991 .

Stage 1 - Dependence - in which two people appear to share one set of ego states. Drawn by Lenhardt as Parent and Adult in one person with the Child in the other, that was similar to the way in which Schiff \& Contribs (1975) diagrammed symbiosis; however, elsewhere in the same book Schiff at al made it clear that they were using an ego state model in which Adult was an adaptation in the service of the Natural Child (for which they drew a fourth circle alongside Adapted Child) and not Adult in the sense of being in the hereand-now. Hence Figure 10 contains my variations of the Lenhardt diagrams excluding Adult from the symbiosis.

Stage 2 - Counterdependence - in which the Parent and Adult ego states which were diagrammed as non- existent in Stage 1 are now shown with dotted lines to indicate that they are being developed. A characteristic of this stage is that the 'little' person wants to break away but also wants to be able to come back, just as a small child will move away from their caregiver but will be checking that they could run back again if they become scared.

Stage 3 - Independence - now both parties are shown as having a full set of ego states but it is as if the 'little' person is operating behind a boundary, whilst still appearing to be in a symbiosis with the other person. The message here is that the 'little' person wants to be left alone; they no longer exhibit the need to come back to the caregiver.

Stage 4 - Interdependence- now both parties are shown as having their full set of ego states, with the 'little' person now fully developed and able to operate in all ego states when they are no longer with the caregiver. Lenhardt (1991) showed a line between as for Stage 3 but I dispense with this and instead show a range of possible transactions.

Gloria Noriega Gayol (1997) pointed out that Berne (1961) recognised four major types of ego state boundary problems, as later summarised by James \& Jongeward (1971), and revised by James (1986) as contamination, laxness, illusion, and rigidity. Noriega went on to describe "the first research study carried out on ego state boundary problems" (p.240), that used a 'Diagnosis Inventory of Ego State Boundary Problems' (DIEP) developed in Mexico City with 20 subjects. However, there appear to be no further references for DIEP (in Google or in the Transactional Analysis Journal).

\section{Interpersonal Boundaries}

Suggested TA concepts: interpersonal distancing, walls and boundaries - and see the end of Part 1 for comments on professional boundaries, which will inevitably be impacted upon by, and impact upon, our interpersonal as well as our personal boundaries.

Kalman Kaplan (1984) defined interpersonal distancing behaviour as "the ways in which individuals approach or withdraw from one another and how they negotiate these tendencies." (p.220). He commented on territoriality as a relatively fixed self-other distance and personal space as an invisible boundary surrounding the person's body. He went on to refer to Hall (1966) and the science of proxemics (use of space as a communication vehicle), with the four spatial zones of: "intimate distance (0 to 18 inches), personal distance $\left(1 \frac{1 / 2}{2}\right.$ to $\left.4 \mathrm{ft}\right)$, social distance $(4$ to $12 \mathrm{ft})$, and public distance (12 to $25 \mathrm{ft}$.) (p.220-221) (italics in original). Kaplan went on to write of a bidimensional view of distancing, with opposing patterns of compensation where an increase of behaviour by one person leads to a decrease in behaviour of the other 


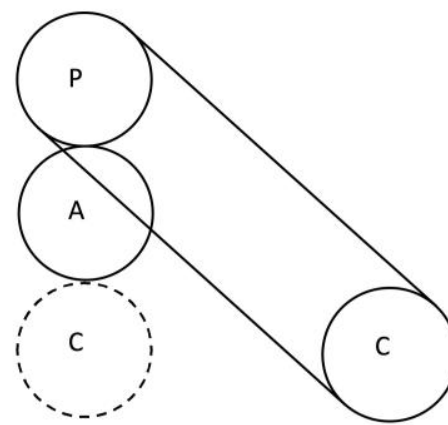

Stage 1 - Dependence

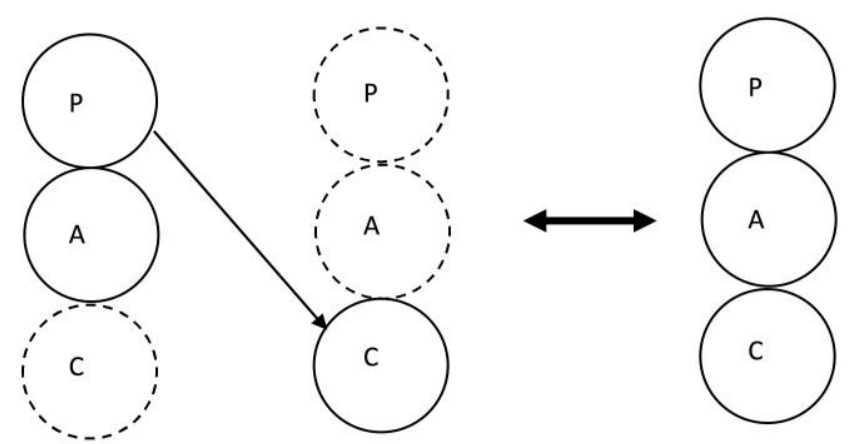

Stage 2-

Counterdependence

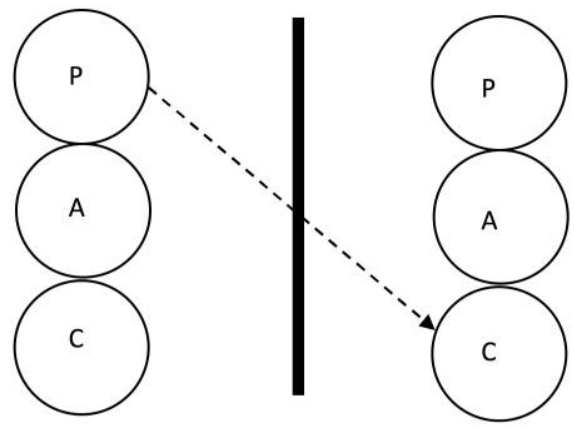

Stage 3-

Independence

Stage 4 -

Interdependence

Figure 10: Hay's 1991 Adaptation of Lenhardt's diagram of stages

(This diagram amended 1 July 2018 after first publication) 


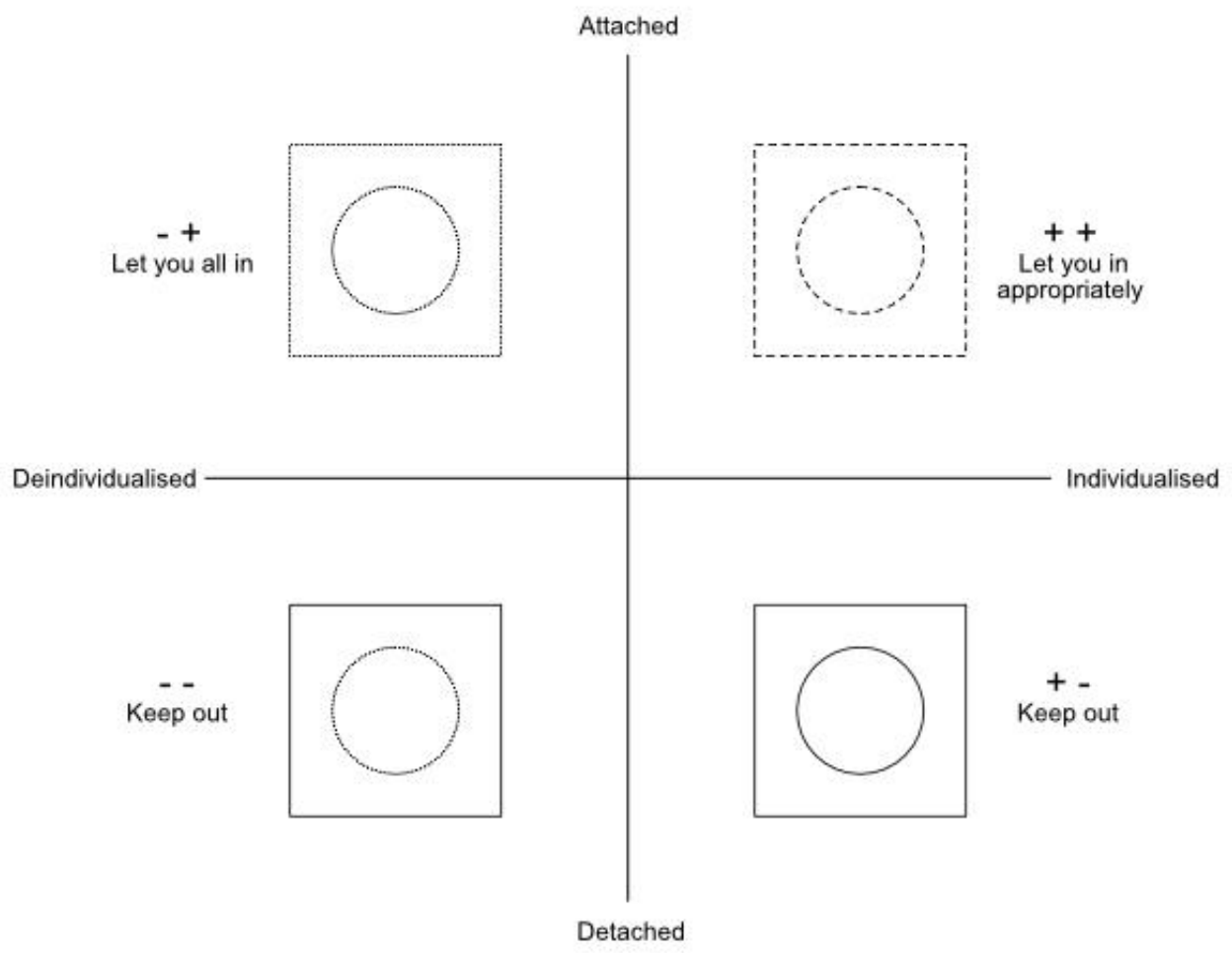

Figure 11: Interpersonal distancing patterns (amended from Kaplan, 1988, p.223)

person, and reciprocity where an increase by one puts pressure on the other for a similar increase. From this can be developed two dimensions: attachmentdetachment and individuation-deindividuation. $\mathrm{He}$ suggests that these can be mapped easily onto the OK Corral (Ernst, 1971 - although Kaplan also references this to Berne, 1961, 1964; and Harris, 1969). 'l' refers to individuation/deindividuation and 'You' relates to attachment/detachment. Kaplan also suggests that this can be illustrated in terms of the interpersonal walls and self boundaries. Figure 11 is an amended version of Kaplan's material.

Magee (1980) had linked interpersonal boundaries to family dynamics when he wrote of how boundaries "determine who participates, and how, in family transactions." (p.328), such that maintenance of boundaries is a latent function of family folklore.

Magee described how emotionally-fixed positions emerge under stress, with:

- pursuers invading other's boundaries by advising, demanding or engulfing;

- distancers erecting rigid boundaries and withdrawing;

- over-functioners doing for others unnecessarily;

- under-functioners seeking support from others unnecessarily.
As another link between interpersonal and family, Stoltz (1985) suggested that eating disorders are commonly caused by lax boundaries due to growing up in enmeshed families with diffuse interpersonal boundaries. Hence, 'foodaholics' lack ownership of their feelings, needs, opinions or ideas and, instead, base their identities on what they incorporate, undigested, from others.

Clark (1999) wrote of internal boundaries set by clients, as a point of contact with the environment and "that space between my known experiences and those experiences that are too powerful to know." (p.292). Clark also refers to Polster \& Polster (1974) for a contact-boundary as a sense of where each person ends, and I-boundaries as an essential element of one's sense of self. These boundaries fluctuate as clients disengage to manage their internal process; as practitioners we need to honour these so the client's relational needs can emerge.

\section{Family/Group/Team Boundaries}

Suggested TA concepts: group imagoes, bystanders, group process

A useful model for considering how family boundaries form is group imagoes, especially as we go into groups later in life with the unconscious expectations of recreating our family of origin, albeit that it may have been influenced also by experiences within groups over the years since childhood. 
Berne (1963) identified four stages of imago development: provisional, adapted, operative and secondarily adjusted. His diagrams looked rather like submarines, with a raised central part like a conning tower that was the slot for the leader. I have renamed the stages to better reflect the processes that occur within them, and suggested the shape be less distinctive so that individuals introduced to the concept are encouraged to use whatever shapes feel appropriate for them.

My diagrams are shown as Figures $12-15$ and relate to Berne's labels as follows:

- $\quad$ anticipatory/provisional - we know we will be in the group and assume there will be a leader, but all others may be in one undifferentiated slot - although we may be unwittingly expecting the others to 'fill slots' as our siblings and other family members and we may expect more than one leader.

- adjusted/adapted - we adjust and augment our imago as we get to know others in the group, whilst deciding whether to be in the group, physically and/or psychologically.

- $\quad$ adapted/operative - we sort out our relationship with the leader(s), deciding whether and how to adapt to them and to others in the group. We may be the leader, in which case we may model ourselves on a leader from our past, often one of our caregivers/parents in childhood, although we may have amalgamated that with other leaders experienced since.

attached or alienated or aggression/secondarily adjusted - apart from what was presumably a typo as there is no primarily adjusted, Berne also wrote as if there would in time be a final stage. I make the point that the outcome may be positive - attachment - or negative - alienation or aggression.

Relating the stages to childhood, and the creation of family boundaries, we can imagine how the child begins somewhat egocentrically, and gradually recognises that their primary caregiver is a separate object' and hence a separate slot in the imago. Then other family members, neighbours, family friends, etc are added to form the adjusted imago. By the time we enter Lenhardt's 'independence' or Levin's 'identity' stage, we realise that we have to adapt, rebel or avoid control by those we regard as leaders and sub-leaders in our 'home' group. Hopefully we move on to feeling that we are attached to the others in the 'home' group, although many will arrive instead at a state of alienation or will experience their own or others' aggression, which will have been a survival strategy.

The nature of the final stage will have a significant impact on how we perceive our group boundary, and how we as transactional analysts might illustrate it in

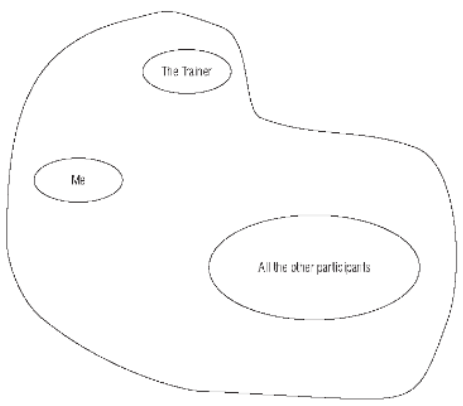

Figure 12: Anticipatory Group Imago (Hay, 2009 p.171)

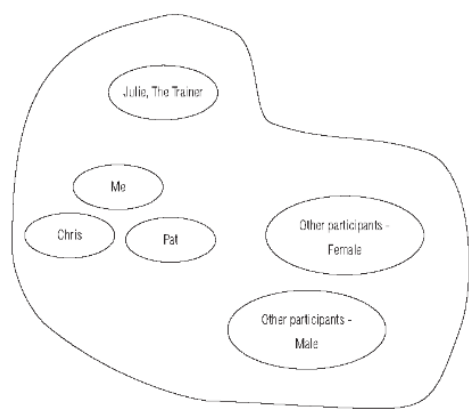

Figure 13: Adjusted Group Imago (Hay, 2009 p. 172) (2009)

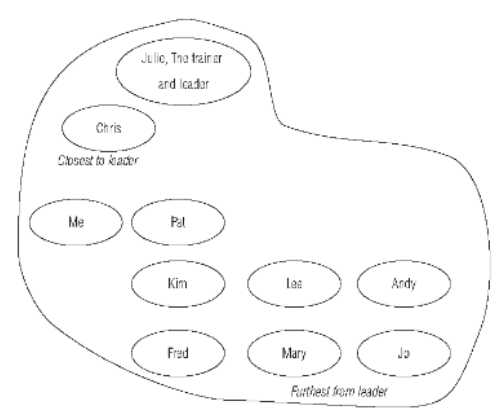

Figure 14: Adapted Group Imago (Hay, 2009 p. 173)

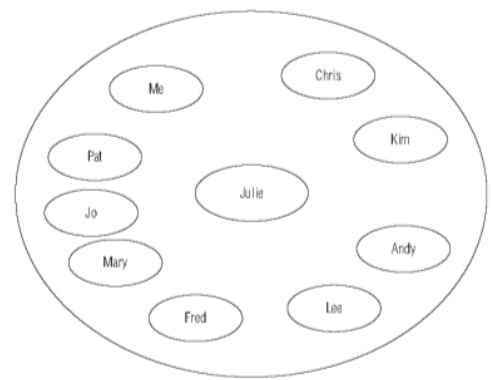

Figure 15: Attached Group Imago (Hay, 2009 p. 175)

terms of the lines used. As shown in Figure 16, a family that arrives at healthy attachment will mean that its members have healthy group boundaries, shown by a line of dashes. Those growing up in alienated circumstances may have the dotted line that represents lack of a boundary, having not experienced what it feels like to be contained within a family group. 

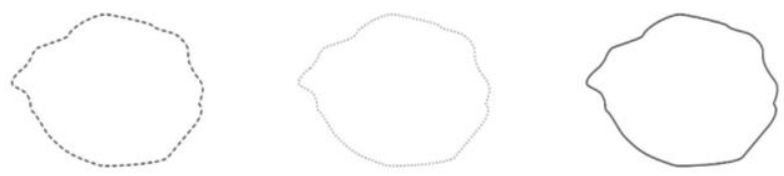

Figure 16: Attached, Alienated and Aggression Group Boundaries

Those for whom aggression was the norm may well have the solid line boundary of a rigid, impenetrable boundary because attention had to be focused on protecting self from aggression within the family so there was no energy available to look outside the group.

I have indicated above that family boundaries become the boundaries for the groups and teams we join - and they will of course also be reproduced if/when we become parents and create new families. In addition to the nature of the boundaries, we may need to consider also the impact on our psychological commitment to boundaries of:

- absent group imagoes (prompted by Clarkson, 1988, 1991 and Tudor, 2013) - where we may still carry a fantasy image even though the group, or family, no longer exists;

- $\quad$ shared group imagoes (Clarke, 1996) - where we are so familiar with each other that our imagoes become shared, making it unlikely any of us will recognise any problems, and hard for any outsider to join the group;

- $\quad$ phantoms (Mazzetti, 2012) - where one of more group members retain a slot for someone who has left the group;

- $\quad$ enemies - Bion (1968) defined having a common energy as a contributor to 'good group spirit', and said the group looks for a leader to recognise an enemy and lead the fight or flight;

- bystanders - although Clarkson (1987, 1993) related these to games, they are just as significant to groups because they reinforce the boundary between members and audience, just as in a theatre. Van Poelje (1995) points out that the nature of the group boundary determines whether, as Jacobs (1987) proposes, bystanders can become followers within a group.

Helena Hargaden (2013) uses Jung's (1978) metaphor of the 'alchemical container' to argue that the therapist and group need to create this because safety exists in the boundary rather than in the contact. She emphasises that firm boundaries allow the enactments of experiences that are impossible to speak of, albeit that co-creation of interruptions to the dyadic relationship ('thirds') may be necessary to avoid any shaming after an enactment.
Adrienne Lee (2014) refers to diffuse, rigid and permeable boundaries in terms of five key aspects of group process:

- containment - as the leaders first concern and including membership, venue and time boundaries;

- leadership - establishing the role of the leader and the major internal boundary;

- $\quad$ responsiveness - how the leader responds go to sleep to each group member;

- $\quad$ interaction - within the group;

- $\quad$ expansion - as group members “... dissolve the psychological outer boundary of the group and expand its relevance to other relationships and parts of their lives." (p.48).

Welford (2014) proposed that all healthy systems have boundaries that are faint yet permeable enough to permit interchange whilst sustaining homeostasis. "A family with a lax boundary has a compromised sense of identity and a tendency to involve nonfamily members in its affairs. A family with a rigid boundary has an overly strong sense of identity and privacy and a loss of contact with other people. (p.321).

Neighbourhood Boundaries (and schools, organisations, corporations, associations, institutions, etc)

Suggested TA concepts: structural diagrams (of groups and organisations), the organisational cone

We can combine neighbourhood with schools and organisations of various kinds because these are where we learn to manage boundaries that go beyond family, team or group. We can use Berne's (1963) simple (core), compound and complex organisational diagrams, as summarised by Fox (1975) in Figure 17.

Blakeney \& Quick (1976) extended Berne's original diagram to apply to a case study description of a consortium of 20 community service agencies, although they treated it as if it were one large group with only a single major internal boundary for a Board of Trustees as leadership and a flexible external boundary because of planned allowance for expansion and contraction of the consortium. They identified four levels of leadership, regarding the President as primary leader, the Executive Director as secondary leader, a third level of technical leaders, and a fourth level concerned with policy.

Berne wrote of the dynamics across organisational boundaries, categorising these into external and internal. The major external boundary is with the environment; the major internal boundary separates leadership and membership. Figure 18 illustrates these, using what Berne referred to as the complicated 


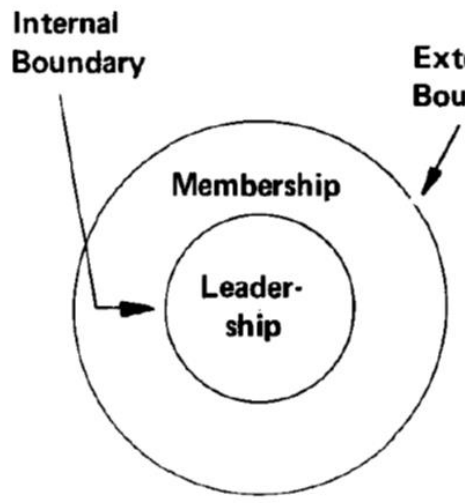

Simple

External

Boundary

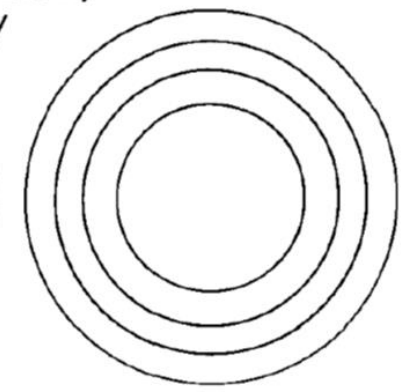

Compound

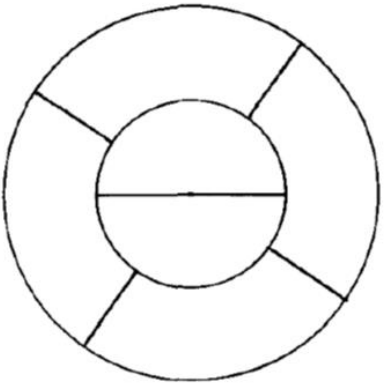

Complex

Figure 17: Structural diagrams. (Fox, 1975 p.349)

[Note: Berne (1963) diagrammed Simple as Ameboid (p. 54) and Compound and Complex as above (p.58)]

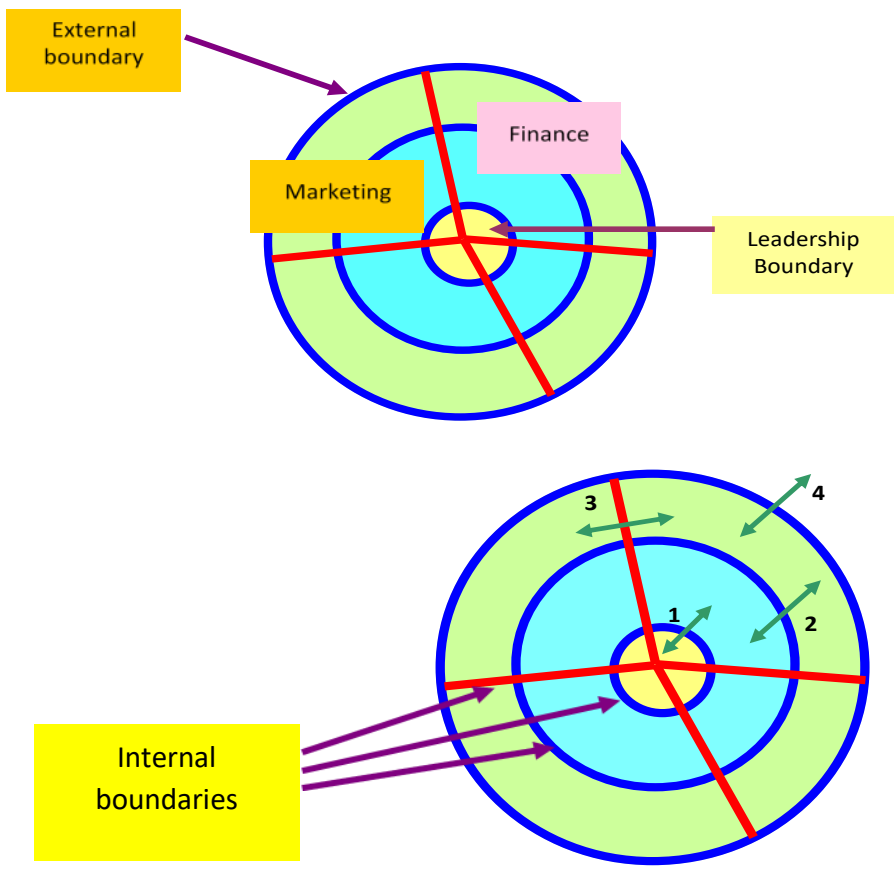

Figure 18: Dynamics across Boundaries

[Note: neither Berne nor Fox drew this 'complicated' diagram that combines levels and functions]

diagram, which he never drew but which he explained as a combination of compound and complex, and which is of course the way in which most large organisations are structured with both levels and functions. There will be psychological forces acting across:

1. the internal boundary between the leadership and the rest of the organisation - where there may be implicit rules about who can become a leader as well as any explicit rules such as expertise or experience. Both implicit and explicit rules may change when a new top leader arrives. Part of the boundary process is the way in which people are appointed to the 'inner circle'.

2. the internal boundaries between different hierarchical levels - in addition to explicit rules about how promotion takes place, implicit boundaries at the psychological level include aspects such as organisational myths, and unwitting and deliberate bias and prejudice. 
3. the internal boundaries between different departments or functions - which are often fraught with tension, either because different departments have been given conflicting objectives, or because there is rivalry between managers.

4. the external boundary between the organisation and the external environment - in a large organisation, there may be complete departments that manage the external boundary, such as Security and Recruitment. How visitors are treated may also be an indicator of how this boundary is construed; it can also be useful to consider what happens when people leave the organisation - are they regarded as traitors and the boundary closes up behind them or are they seen as helpful ambassadors of the organisation in the future.

Hay's Organisational Cone

One problem with Berne's diagrams, because they are two-dimensional, is that visually it gives the impression that leaders can only be appointed from within the membership - there is no link between the major external boundary and the leadership. This is resolved within the diagram of the Organisational Cone (Hay, 2016). This is a three-dimensional model, based on the complicated version from Berne but drawn to resemble an ice cream cone. In this way, there is an external boundary at all hierarchical levels of the organisation and for every function. People can come into the organisation and leave it at any level and related to any department; I indicate on the diagram how the external contacts vary so that senior management manage boundaries with the government, regulators, shareholders and so on, frontline workers manage boundaries with customers/service users, and middle managers deal with suppliers, distributors and other organisations that are linked to the activities of the organisation.

We can relate the organisational cone model to a neighbourhood and school, especially as those will be the places where we first learned to expect to have the various internal and external boundaries and the dynamics across them. We can imagine, for instance, that there will be some people within a neighbourhood who become the politicians, dealing with outside authorities on behalf of their neighbours. Others may be the equivalent of middle managers, running the various service organisations and shops and dealing with bringing in goods and services and sending out whatever is being produced within the neighbourhood. When it comes to the frontline workers and the customers/service users, these may be the same people, albeit occupying different categories at different moments in time. An individual may, for instance, be a shop assistant or a parking warden at one time, and be the customer in the shop or the car driver being given a parking ticket at a different time. The politicians and those running businesses (the equivalent of top and middle managers) may of course also be customers/service users at some moments in time, although they may of course go out of the neighbourhood for what they need.
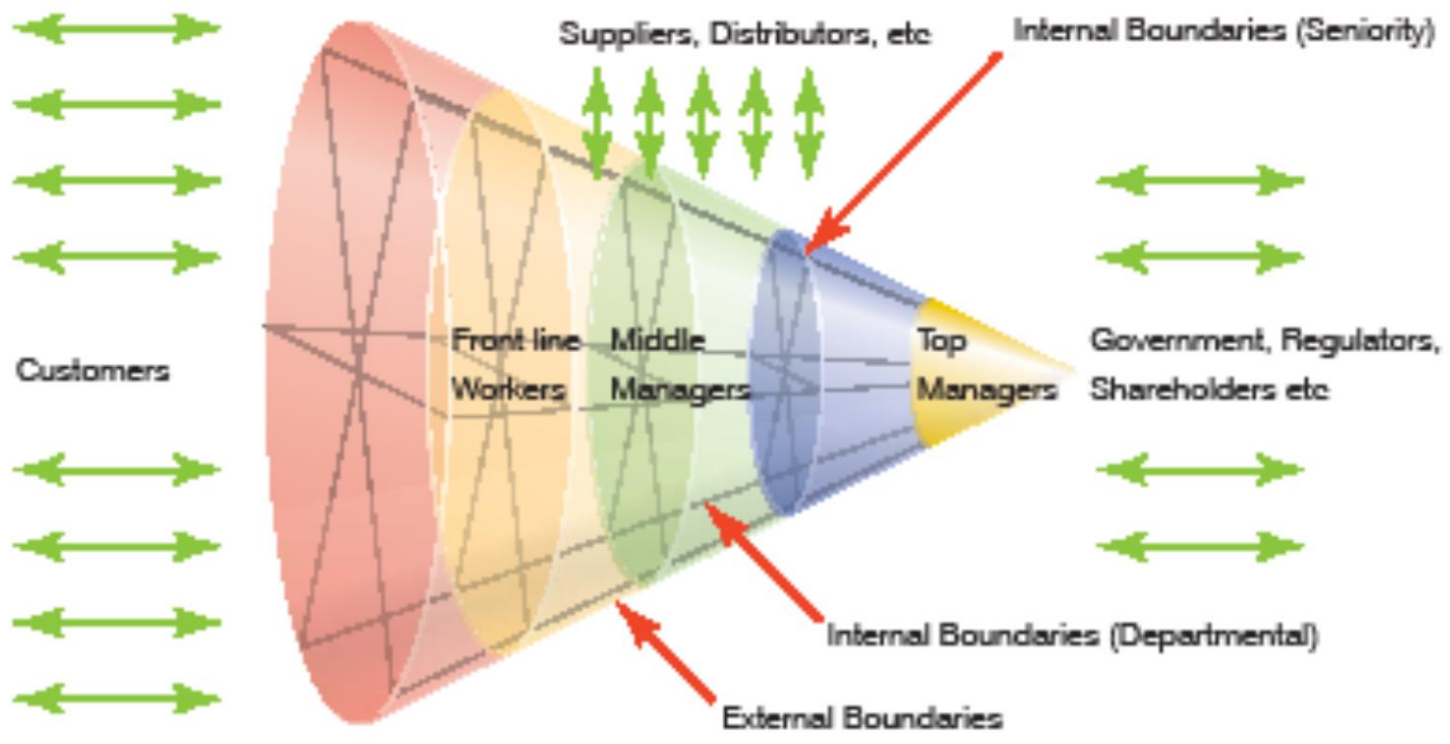

Figure 19: Hay's Organisational Cone (Hay, 2016, p.20) 
We can even relate the model to the way in which gangs operate. The gang leaders are likely to be the ones threatening or bribing the authorities; the frontline workers are the gang members who carry out the dayto-day illegal activities; the middle managers are just that - the conduit between the top management and the frontline. Everyone involved is very well aware of the external boundaries - you cannot just choose to join a gang - and the internal boundaries between the hierarchical levels and the functions and roles.

\section{Place and Planet: Boundaries beyond Neighbourhoods/ Organisations \\ Sailship Success Metaphor}

Over the years, I (Hay, 1995, 2004a, 2017) have developed a model of an organisation based on the metaphor of a ship, which is allows us to consider such an organisation facing the elements of the sea and the weather. As can be seen in Figure 20, the ship has two sets of sails - the 'hardware' strategies, structures and systems, and the 'software' of (psychological) safety, strokes and stimulation. There is also a pennant flying with a symbol and slogan, and there are staff and a skipper on the ship.

This model allows us to think of the organisation as part of a fleet, so we can consider the boundaries of the particular ship and the boundaries of the fleet they are sailing within. We could even think about the boundaries of the particular ocean if we chose to. We can also consider the condition of the sea and the weather. These are happening outside the boundary of the ship and cannot be controlled from within that boundary - we can only make sure that we have as good a lookout as possible. Metaphorically, the sun may be shining or there may be storms; there may be snags that would ground the ship, or competitors sneaking up on us like submarines, or sharks waiting to devour anyone who leaves the ship - or maybe anyone who tries to approach the ship.

The boundary of the ship is therefore the physical limits of it where it comes into contact with the environment, and that boundary may need constant attention to protect it at times when the environment becomes negative.

If the organisation is part of a fleet, there will be a fleet boundary and the position of each ship within the fleet will be significant. If we are the big ship in the middle, we may be being protected, especially from pirates, by smaller ships around us. However, if we are a smaller ship sailing on the edge of the fleet, then in addition to being more at the mercy of the weather, we may also be a convenient sacrifice if pirate ships come along in the form of competitor organisations or those seeking acquisitions or mergers.

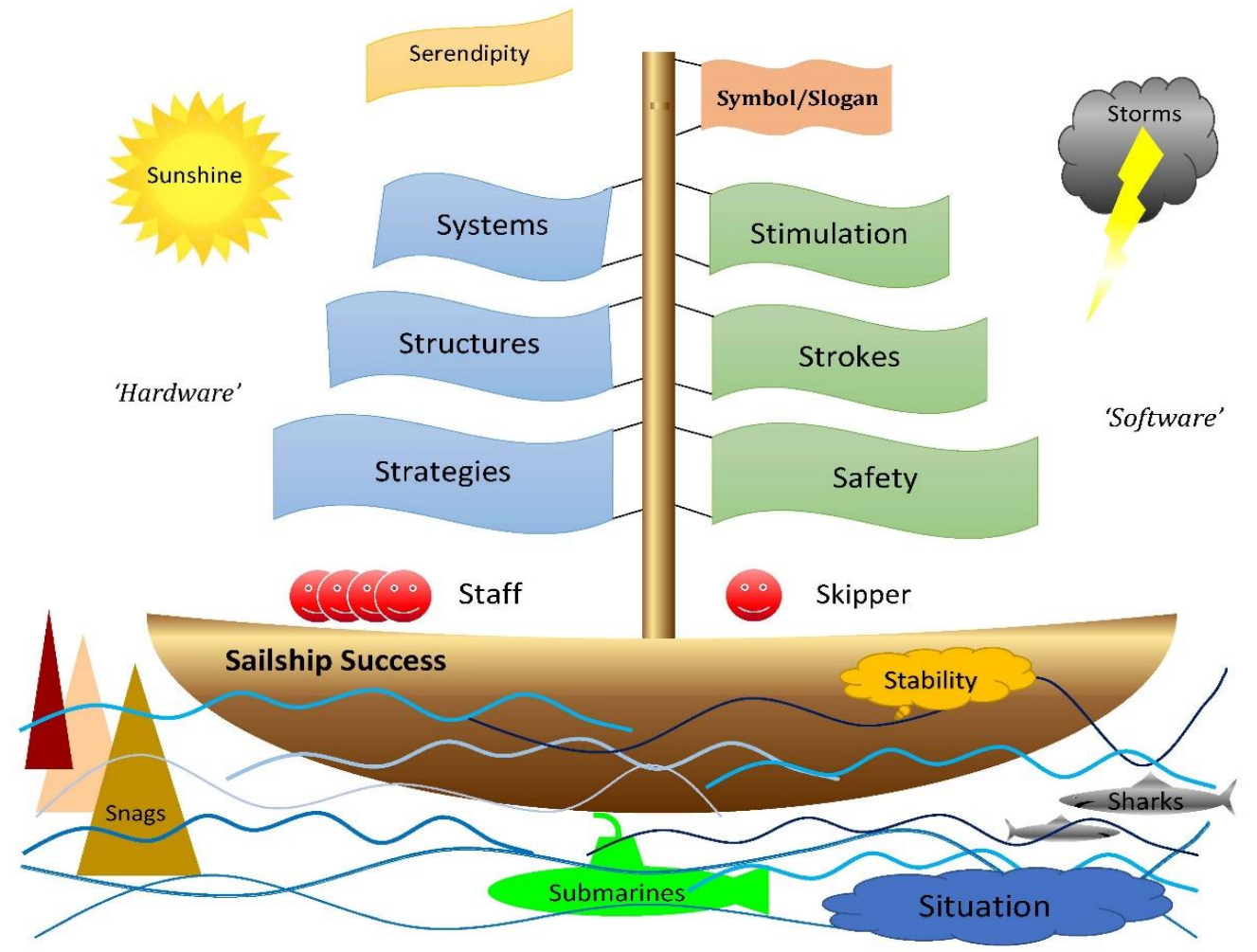

Figure 20: Sailship Success (Hay, 2017, p.6) 
If we are practitioners who work with organisations, such as consultants or coaches, we may need to think about the size of our own ship and how easy it will be for us to cross the boundary of the client organisation. If we are part of a big enough ship, such as a household name consultancy company, it may be easier to 'get permission' to send our own sailors on board. However, if we are small, perhaps little more than a skiff, then the large organisational sailship may choose to ignore us, or fail to even notice us, or be too large for us to get alongside

\section{Planetary Changes}

The publication of a special issue on 'Identity Integration - Boundaries' of the Transactional Analysis Journal in 2018 as this paper was being completed seemed fortuitous but in the event there were few mentions of boundaries. One by a non-TA author, Françoise Sironi (2018) did, however, mention geopolitical psychology, planetary changes and emerging identities. Writing of her work with clients who have been subjected to identity metamorphosis through processes such as torture, exile, collective violence, cults and abusive psychotherapists, she suggested that there is a geopolitical unconscious alongside the increasing rate of global geopolitical changes.

She explained that geopolitics studies the history of borders, emergence of new states or territorial entities, claims for independence, the reasons for disappearance of certain peoples, groups, or nations, territorial conflicts, new political, economic and religious ideologies, and rearrangements of global alliances, and on a planetary scale. Clinical geopolitical psychology studies the impacts on humans - when we listen to clients we need to hear how geopolitics affects their subjectivity.

It appears, therefore, that we will increasingly need to account in work with clients for the boundaries of countries, continents, and different environments. This is something that may be taken for granted when working with multinational organisations and governments - Sironi reminds us how these wider boundaries impact on everyone.

\section{Power and Boundaries}

Fanita English (1979) quoted $18^{\text {th }}$ century philosopher Jean-Jacques Rousseau for the notion that everyone emerges from childhood with a slave or tyrant mentality, labelling them respectively as Type I, helpless victims or rebels who seek strokes from powerful Parent figures, and as Type II, helpful yet bossy Powerful Parents who start out as rescuers but shift to persecutor and eventually to victim (no initial capitals in original). Hence, Jones in Guyana, and Hitler before him, became the Great Leader or the Grand Inquisitor, who could offer the slaves
(Dostoevsky, 1957) someone to worship and hence an escape from autonomous functioning. English points out how people appear to function more effectively in such circumstances, as they no longer have to deal with contradictory or unpleasant emotions and have now got a stable conception of the object of life (Dostoevsky).

Alan Jacobs (1987) continued with English's questions on which his article was based: "Why do people join political, religious, professional, or social movements, of whatever size, and surrender so completely, giving up everything including their lives, their fortunes, their families? What needs do people have to find and love a marvellous parent who has all the answers, and in his or her name, to even commit murder and suicide?" (p.59). He goes on to refer to various political, religious and social movements that seek to impose their own view of reality and hence to control large numbers of followers - such as Nazis in Germany, Bolsheviks in Russia, Khomeini in Iran, Pol Pot in Kampuchea, as well as fundamentalist religious groups including those of Jews, Christians and Muslims. The atmosphere that allows such autocratic structures to emerge is one of "economic turmoil, war, and social, religious, or political oppression [which] exacerbate personal existential fears..." (p.60). He goes on to suggest that there will be masters, followers, bystanders, sources of evil, slaves, and resisters.

Several years later van Poelje (1995) suggested that in the current climate of rapid changes and globalisation of local problems these ideas become more relevant. It is almost as if the complexities and the uncertainties of modern life lead people to look to their leaders for certainty. This is a recipe for autocratic systems to begin to take hold. She develops Berne's (1964)/Jacobs (1987) by using thicker lines to show that the external boundary is permeable allowing bystanders to be recruited during the early stages. Then the external boundary is closed, and lieutenants are appointed to manage internal agitation. Only Lieutenants can cross the external boundary to convert followers. To further strengthen the external boundary an enemy or Object of Evil is identified (Jacobs 1991). For example, Enemies for Hitler were Jews and Gypsies and for US President Bush they were Terrorists and the 'Axis of Evil'.

The Lieutenants deal with any agitation and now may be divided in their tasks, some managing the internal group process (Police) and others managing the external group process (Army). Those managing the external process will be responsible for acquiring resources, including labour. Where this labour is forced they are known as Slaves. Finally, Resisters emerge. They refuse to accept the symbioses and fight to overthrow the Master. 


\section{Practitioner Boundaries}

As professional practitioners, we operate within our own nested circles of boundaries. An obvious focus of attention is needed on our professional identity and how this impacts on our work with clients. Non-TA author Peterson (1992) wrote of how violations often occur because the practitioner fails to recognise that the professional relationship is not one of equality. The practitioner has personal significance, power or authority within the relationship with the client. Peterson emphasised the need to find a middle ground between misuse of power from infantilising clients versus denying there is any power differential. Power violations may be due to:

- role reversal, when the client becomes the caretaker;

- $\quad$ a secret, such as keeping information about their behaviour from the client;

- a double bind, when the client has to choose between doing what the professional wants and refusing to do so;

- professional privilege, where the practitioner's agenda takes precedence.

More recently, another non-TA author, Lifshitz-Assaf (2017) reported on a longitudinal field study of R\&D (Research \& Development) professionals at NASA which demonstrated that identity refocusing was needed for these professionals to be able to adopt open innovation - meaning that they had to transcend their professional knowledge boundaries if they were to be able to recognise the quality of innovative solutions proposed by non-professionals. The identity change needed was from being the one who generated solutions into being a solution-seeker. Although TA professionals are, hopefully, well aware that they are aiming to facilitate their clients into generating their own solutions, Lifshitz-Assaf's findings are relevant when we consider that her observations were related to the impact of having professional knowledge and believing that such professional knowledge was restricted to our own profession. She identified four different types of boundaries, as shown in Table 3.

As well as considering how the TA community incorporates or rejects theories and approaches from outside TA, we might also consider how having different competencies for the different fields of TA application makes the boundaries between the fields more significant. As an individual, we need also to consider how our own professional boundaries may be operating outside our awareness, and how we might address this within supervision. The encouragement to have supervision from a professional within the same field of TA application may, ironically, be reinforcing boundary fencing.

\begin{tabular}{|c|c|c|}
\hline $\begin{array}{l}\text { Type of } \\
\text { boundary }\end{array}$ & $\begin{array}{l}\text { Knowledge } \\
\text { flows }\end{array}$ & Illustration \\
\hline $\begin{array}{l}\text { Boundaries } \\
\text { dismantled }\end{array}$ & $\begin{array}{l}\text { From “'The } \\
\text { lab is my } \\
\text { world' to } \\
\text { 'The world is } \\
\text { my lab"” } \\
\text { (p.16) } \\
\text { (italics in } \\
\text { original) }\end{array}$ & \\
\hline $\begin{array}{l}\text { Semi- } \\
\text { permeable, } \\
\text { perforating }\end{array}$ & $\begin{array}{l}\text { Innovation } \\
\text { may occur } \\
\text { inside and } \\
\text { outside the } \\
\text { organisation }\end{array}$ & \\
\hline $\begin{array}{l}\text { Feigned } \\
\text { semi- } \\
\text { permeable, } \\
\text { feigned } \\
\text { perforating }\end{array}$ & $\begin{array}{c}\text { Stated } \\
\text { publicly as } \\
\text { open but } \\
\text { ideas from } \\
\text { outside are } \\
\text { segregated }\end{array}$ & \\
\hline $\begin{array}{l}\text { Boundary } \\
\text { fencing }\end{array}$ & $\begin{array}{c}\text { Inside stays } \\
\text { inside, } \\
\text { outside } \\
\text { stays } \\
\text { outside }\end{array}$ & \\
\hline
\end{tabular}

Table 3: Knowledge Boundaries- adapted from Lifshitz-Assaf (2017, p.15)

\section{Part 2: Bridges}

A key way to develop bridges across our own boundaries will be supervision. I begin Part 2 by reviewing two models of the stages/domains of supervision. We can also gain insight by considering unconscious processes within the supervision process (e.g. parallel process, transference, projection). The comparative script system provides a bridge from client to practitioner, and material on dual relationships reminds us of our ethical responsibilities.

I go on to consider how we may have created problematic boundaries between the TA fields of application, and what we might do about that. I conclude with a framework that brings us back to how we bridge boundaries in our interactions with individuals.

\section{Supervision}

Hewitt (1995) presented a model that he named 'cycles of psychotherapy', which he said could be applied to psychotherapy, counselling and supervision (although he did not give much information about its use in supervision within the article). He also commented that he would concentrate on the first and 
final phases of therapy because he believed that previous TA literature had emphasised the middle phases. He proposed that the cycle be based on a metastudy conducted by Steenbarger (1992) where it was suggested that successful treatment could be divided into three phases: engagement, discrepancy and consolidation. Hewitt proposed that these be named contact, content and consolidation, and then he added a fourth which he called conclusion. He pointed out that he presented these as a cycle rather than a sequence, so there would be less temptation to treat therapy as linear when clients often need to move backwards and forwards through the stages.

I propose that additional stages might be added to Hewitt's model, so that it becomes: contact, contract, content, capacity, consolidation and conclusion. Hewitt mentions discounting only briefly in his paper, whereas we can relate these stages to the treatment levels in the discount matrix (Schiff \& Contributors, 1975), converted into the steps to success (Hay, 1996) model as Figure 21, to demonstrate ways in which supervisors can help supervisees become aware of their own discounting and differentiate it from genuinely not knowing something.

Success - Conclusion

- what will supervisee

do now - and how will

they avoid sabotaging

themself

Strategies - Consolidation

- creating an implementation plan

Skills- Capabilities - does the supervisee have the skills - or how can they develop them

Solutions - Content - analysis and consider what options might there be

Significance - Contract - what seems to be the issue, what needs to be worked on in supervision

Situation - Contact - reminder of supervisory relationship, how advanced is supervisee, expectations about nature of supervision

Figure 21: Stages of Supervision and Steps to Success

Evans (1998) proposed a developmental-relational approach to supervision, on the basis of research
(Bernard \& Goodyear 1992, Stoltenberg \& Delworth 1987) showing that supervision that matches the supervisee's structure and style was more likely to generate successful outcomes. Evans commented that "The supervisory relationship differs from the therapeutic relationship in that it is more task oriented, with time spent considering information, opinions, and suggestions. The supervisor assumes the role of supporter, teacher, monitor, advisor, evaluator, instructor, and consultant, imparting expert knowledge, making judgements on supervisee performance, and acting as gatekeeper to the profession. The supervisor has the dual responsibility of holding in balance the needs of the supervisee and the best interests of his or her clients." (p. 288). Evans went on to link to supervision the four stages, or domains, of self experience and social relatedness which Stern (1985) had described. She also included a series of figures that used dotted lines for permeable boundaries and solid lines for boundaries to keep self in or others out: each contains a circle for the individual and a square for the environment and examples are shown in Figures 22-28.

- emergent self-experience and relatedness Evans writes of how some new supervisees are like infants with innate organising potential but lacking the clearly identified self-boundaries that would have developed within a good-enough facilitating environment; such supervisees may indicate an arrested developmental position by being uncertain or unclear and hence inviting countertransference of persecutory or rescuing superiority; some may have learned to adapt and are keeping hidden their sense of self. Hence, supervisors need to bracket their own ideas and support supervisees in evaluating and integrating their learning rather than accepting the learning from others.

- core self-experience and relatedness supervisees are now less dependent and begin to express what they want from supervision; adversarial transference needs may become significant as they test their personal boundaries against the boundaries of others. Some may become extremely self-reliant or act as caregivers in order to hold onto their fragile sense of self by avoiding closeness. Supervisors need to act as self-regulating others who encourage growth in ways that balance challenge with sufficient support. Exploration of transference and countertransference becomes particularly useful in helping supervisees identify their own issues.

- $\quad$ subjective self-experience and relatedness supervisees (infants) move from the need to regulate their self-experiences to the need to 
share them, which Evans likens to emotional attunement (Erskine 1993), empathy, positive regard and congruence (Rogers 1990) and I-Thou (Buber 1923/1970). Evans suggests that supervision for the supervisor may be helpful for this stage, when a new collegial quality may enter the supervisory relationship.

- verbal self-experience and relatedness supervisees (infants) can now share their ideas of self-experience and have a capacity for abstract observation; they are now competent practitioners, self-supporting and self-reliant, and may have become supervisors themselves.

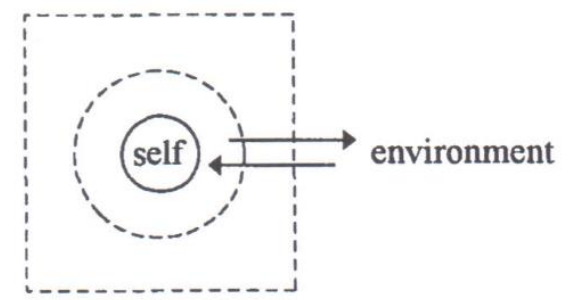

Figure 22: Emergent Stage (Evans 1998 p. 290)

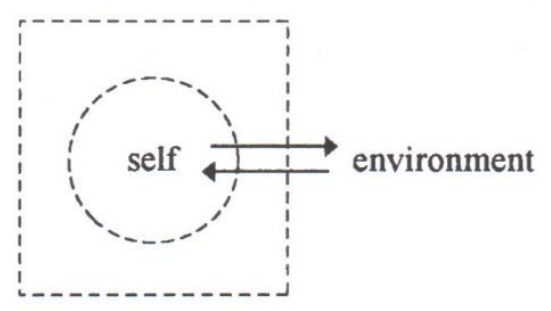

Figure 23: Adaptive Emergent Stage (Evans 1998 p. 291)

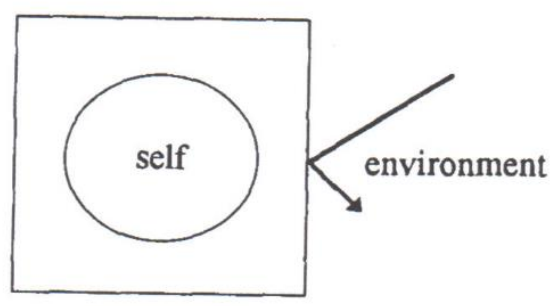

Figure 24: Compulsive Self-Reliant (Evans 1998 p. 292)

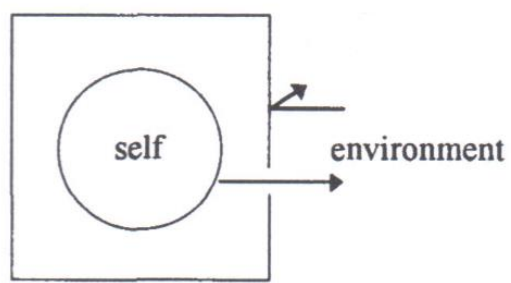

Figure 25: Compulsive Caregiver (Evans 1998 p. 293)

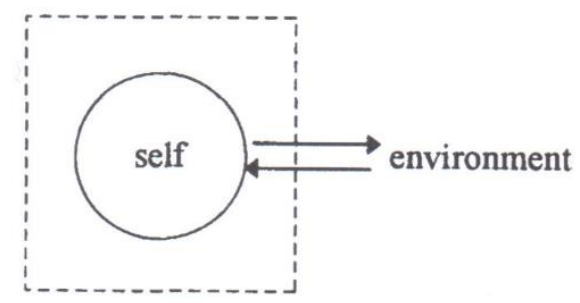

Figure 26: Healthy Core-Self Relational Position (Evans 1998 p. 293)

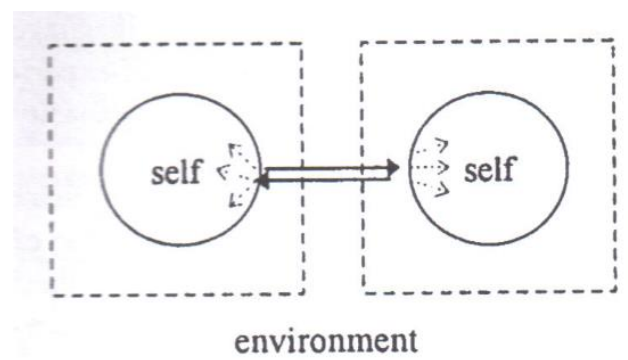

Figure 27: Intersubjective Stage (Evans 1998 p. 295)

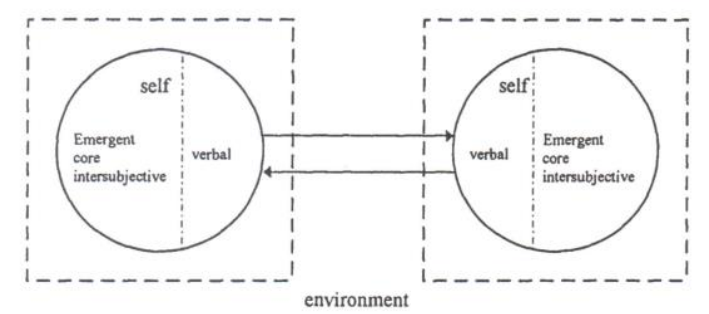

Figure 28: Verbal Stage (Evans 1998 p. 296)

\section{Unconscious Processes}

Parallel Process

Parallel process was first described by Searles (1955), who referred to it as the reflection process. Although not a TA concept, it is invaluable for drawing our attention to underlying dynamics within a process, and it is mentioned here because it can provide so much insight into other aspects of the supervisory relationship. It refers to the phenomenon whereby dynamics between people are repeated between others. It often happens that practitioners react to clients in just the way that the client is reacting to their own contact. For example, "my colleague is so obstinate" may have the practitioner thinking "this client is so obstinate", and then the supervisor thinks "this supervisee is so obstinate". Clarkson (1991) suggested that it consists of projective identification resulting from "mutually interacting hypnotic inductions which occur out of awareness in the form of ulterior transactions." (p.174).

Usually diagrammed with an infinity symbol, in Figure 29 we show this rotated into a vertical position to make the point that a parallel process may 'go in either 
direction' - practitioner and supervisor may repeat the dynamics of the client with others, or the dynamics of the supervisor may be transferred via the practitioner to the client, hopefully because the supervisor is modelling a more appropriate way to behave. It is always possible, of course, that the dynamics of the practitioner may become paralleled by the supervisor and by the client.

Parallel process shows up within organisations, where the dynamics between managers may be repeated between their teams - when the managers of finance and marketing are in conflict - in private - their teams somehow sense this and also get into conflict. When teachers in schools are feeling ignored by the head teacher, the pupils will feel ignored by their teacher.

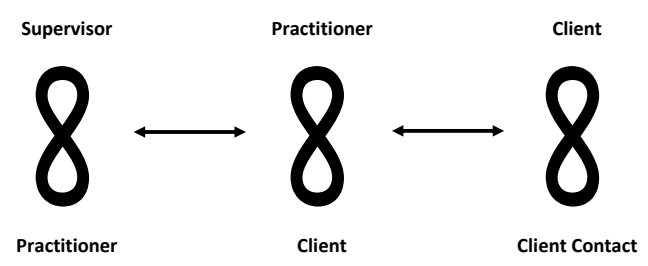

Figure 29: Parallel Process

Transference and Countertransference

I (Hay, 2009) have simplified material on transference by authors such as Novellino \& Moiso (1990), Clarkson (1991) and White (1998) into the formats shown in Figure 30 . The following examples may be as a result of a parallel process that emerges from the client or the supervisor but may instead be the result of the practitioner's script issues. Either way, it makes sense for the practitioner to consider the possibility of transference and countertransference before engaging in a supervision session - there is a shared responsibility for the supervisory process.

Concordant transference - there is a risk that those of us engaged within the TA community may assume that we are all very similar because we have a shared set of TA principles. We may even choose our supervisor because of perceived similarities, and hence lose the opportunity of the learning that might come from interacting with someone different.

Competitive transference - if you believe that you are already a very experienced practitioner, you may be unconsciously competing with the supervisor, particularly if you feel that they are telling you what to do with your client rather than helping you to reflect and analyse. Alternatively, you may feel competitive about proving that the kind of clients you are working with are much more challenging than the clients your supervisor may be used to.

Conflictual transference - within a professional context, the supervisor is in a position of authority because they have a responsibility to ensure that you are complying with professional norms. This may lead to an attempt at rebellion (your Child against the supervisor's Parent) if you feel that they are somehow telling you what to do. If you are an experienced practitioner from a different approach (e.g. a management consultant with a psychotherapist supervisor) you may instead attempt to occupy the Parent position yourself, especially if you think that they have had less experience, or less relevant experience, than you as a practitioner.

Co-dependent transference - this is probably the most common transference to occur within supervision. The supervisor may well be more experienced than you (and not just as a supervisor), they will have already passed some of the professional exams, they may also be older than you, and they probably know more people within the TA community then you do. It is very easy to project onto them the face of a teacher when you were a child at school, or indeed any other authority figure, and then expect that they will take care of you and your needs. The opposite may also occur if you are a very experienced practitioner and they are a beginning supervisor, or a supervisor who is learning how to give supervision in a field of practice in which they have not worked themselves.

\section{Projection and Projective Identification}

Projection and projective identification are similar to transference except that instead of relating to each other, the client projects their own experiences or feelings at an unconscious level into rather than onto the practitioner, who may then identify with those experiences or feelings.

Stark (2000) writes that "Projection is an intrapsychic mechanism and, as such, requires the presence of only the projector; the therapist is not a participant in the patient's internal drama. Projective identification, on the other hand, cannot exist in a vacuum and requires the presence of both the projector and the recipient; the therapist is now very much involved as an actual participant." (p.265). For example, a client may project their own feelings of incompetence by claiming that the practitioner is incompetent, although the practitioner knows they are being competent. With projective identification, the practitioner will actually feel incompetent (even though they are not).

Hargaden \& Sills (2002) write “. . . projective identification . . . is a more intense type of transference particularly needed by patients where there has been significant fragmentation in the early development of the Child ego ( $\left.\mathrm{C}_{0}\right)$ " (p. 50).

\section{Comparative Script System}

One of the risks for a practitioner is that client material will trigger our own issues, and we may unwittingly respond in a way that has more to do with our own 


\begin{tabular}{|c|c|c|}
\hline & & t self \\
\hline & Competitive & Concordant \\
\hline & $\begin{array}{l}\text { We project elements of our own Child } \\
\text { or Parent ego state onto the other } \\
\text { person and then get into a } \\
\text { competitive symbiosis about whose } \\
\text { Child or Parent will take precedence }\end{array}$ & $\begin{array}{l}\text { We project elements of our own Child } \\
\text { or Parent ego state onto the other } \\
\text { person and then believe they are just } \\
\text { like us and we are empathising with } \\
\text { each other }\end{array}$ \\
\hline in relating & Conflictual & Co-dependent \\
\hline & $\begin{array}{l}\text { We project elements of 'a third party' } \\
\text { onto the other person and then feel } \\
\text { we must 'fight' in a Parent-Child or } \\
\text { Child-Parent interaction }\end{array}$ & $\begin{array}{l}\text { We project elements of 'a third party' } \\
\text { onto the other person and then seek a } \\
\text { Parent-Child or Child-Parent } \\
\text { symbiosis }\end{array}$ \\
\hline
\end{tabular}

Appear to get

on well together

Project someone else

Figure 30: Transference Formats (Hay, 2007 p. 16)

needs than the clients. Sills \& Mazzetti (2009) presented the comparative script system as a tool for supervisors, commenting in their abstract that it could be useful as "... a framework for focusing on the key issues in supervision; a practical instrument for understanding and visually representing transferencecountertransference dynamics; and a clarification of the boundary between supervision and therapy." (p.305). Based on a previous article published within the UK by Sills \& Salters (1991), the version by Sills \& Mazzetti shows the diagram for the comparative script system as a circle divided into quarters containing a sequence of: $A$ - repetitions of the dynamics of original experiences and events; leading to $B$ - meaning making, assumptions about self, others, and the world; leading to $\mathrm{C}$ - patterns of thinking and feeling, expectations and imaginations; leading to $D$ observable behaviour and communication style, which in turn leads back to $A$. They indicate that $D$ is how we interact with others, and that a stimulus enters $C$ to start off the sequence. They also label $A$ and $B$ as the Past - There and Then, whereas $D$ and $C$ are labelled as Here and Now.

Sills \& Mazzetti suggest that the diagram can be used in supervision, giving an example based on a client's script system with $A$ as a bleak, friendless childhood; leading to $B$ where the belief is that others have fun and I am alone; leading to $C$ where the pattern is to feel envious and alienated; leading to $D$ where the observable behaviour is passive and the client does nothing and withdraws. They also suggest that two mirror-image circles might be drawn, with details entered for the client and the practitioner, as a way of exploring similarities and differences, and considering how that might impact on the way the practitioner is working with that client. If drawn for several clients, it might also indicate particular areas for development of the practitioner. They comment that the supervisor should not address any of the details about the past but I have proposed (Hay, 2014) that this restriction is unnecessarily cautious provided the supervisee is able to discuss their own script issues without regression.

Figures 31 and 32 show the original Sills \& Mazzetti diagrams. Tables 4 and 5 comprise an example showing the before and after supervision versions of the comparative script system applied to a client receiving relationship counselling.

\section{Dual Relationships in Supervision}

Cornell (1994) reviewed previous literature on dual relationships, pointing out the increasing struggles at that time with issues related to professional ethics and liability, and a growing tendency towards conservatism and rules whereas the ITAA had sought to avoid rules while still providing guidelines and principles. 

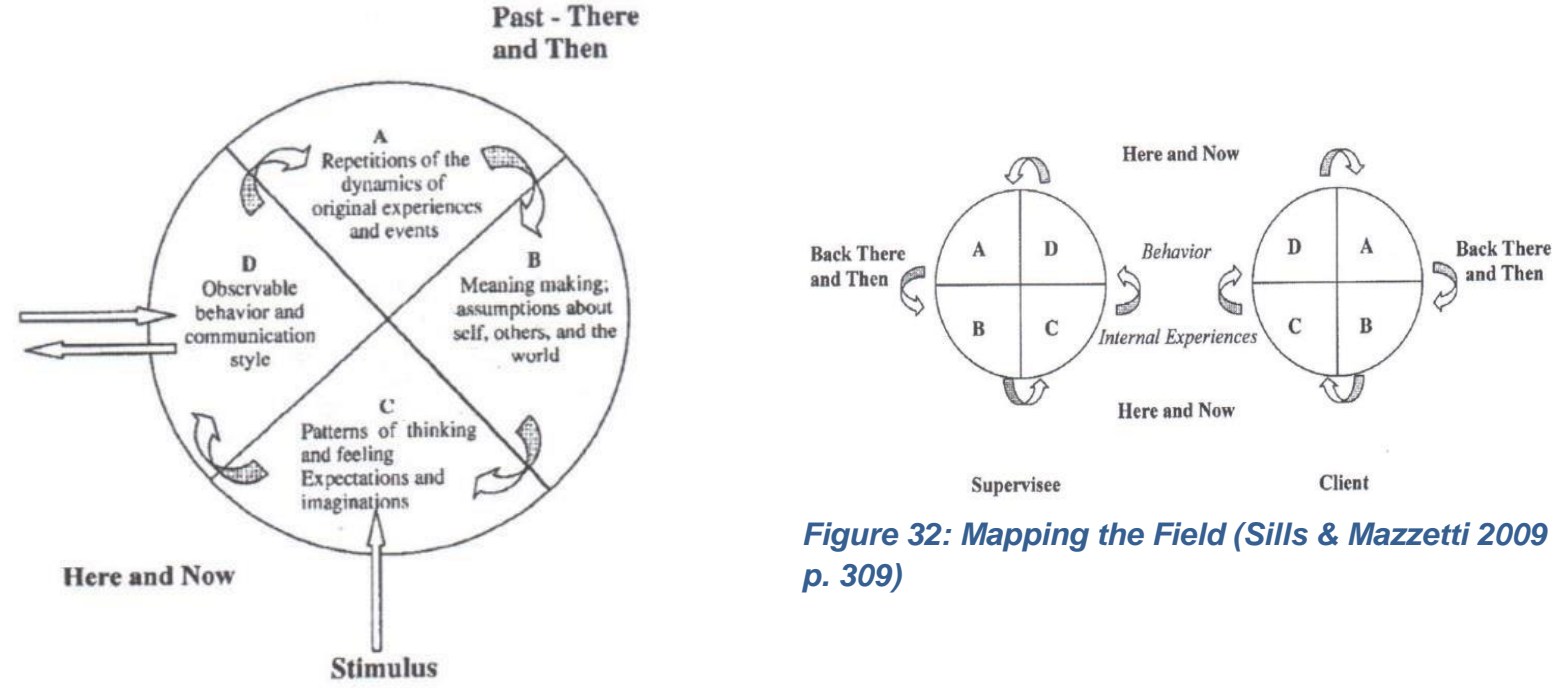

Supervisee

Client

Figure 32: Mapping the Field (Sills \& Mazzetti 2009 p. 309)

Figure 31: Comparative Script System (Sills \&

Mazzetti, 2009 p. 306)

A: repetitions of

dynamics of original experiences and events

B: meaning making: assumptions about self., others and the world

C: patterns of thinking and feeling: expectations and imaginations

D: observable behaviour and communication style (psychologically) violent father, 'unaware' mother - I felt rebellious and hated him

He's bad; I'm OK, They're not OK, Get rid of (Ernst 1971)

with this client: can't decide what to think or feel, invited to nurture and also to persecute; wondered if client really unlucky with so many problems or is she fantasising

$2^{\text {nd }}$ husband alcoholic (like hers), made him leave when he became violent, did not take him back

Table 4: Example of comparative script system before supervision

\begin{tabular}{|c|c|}
\hline $\begin{array}{l}\text { B: meaning making: } \\
\text { assumptions about self., } \\
\text { others and the world }\end{array}$ & $\begin{array}{l}\text { My father had PTSD from } \\
\text { WWII; my mother was dealing } \\
\text { with many pressures without } \\
\text { support }\end{array}$ \\
\hline $\begin{array}{l}\text { C: patterns of thinking } \\
\text { and feeling: expectations } \\
\text { and imaginations }\end{array}$ & $\begin{array}{l}\text { still not sure how much client } \\
\text { says is true versus fantasy; this } \\
\text { could be because we shut } \\
\text { down in the face of extreme } \\
\text { stress }\end{array}$ \\
\hline $\begin{array}{l}\text { D: observable behaviour } \\
\text { and communication style }\end{array}$ & $\begin{array}{l}\text { checked that her process of } \\
\text { coming to terms is not a } \\
\text { familiar pattern for her; } \\
\text { emphasised that she can } \\
\text { return to counselling in the } \\
\text { future }\end{array}$ \\
\hline
\end{tabular}

B: meaning making: assumptions about self., others and the world

C: patterns of thinking and feeling: expectations and imaginations

future violent father, submissive mother-client felt rebellious and scared

I'm bad; I'm not OK, They're not OK, Hopeless (Ernst 1971)

overwhelmed, expect others to be violent, feel Victim, Hindu belief of being punished for previous life

rebellious by marrying out of caste, husband violent, made him leave but took him back

Table 5: Example of comparative script system after supervision 
Cornell also pointed out that the ITAA code of ethics was written in terms of relationships with clients whereas we need to consider also relationships with trainees.

Cornell described how in the early years of TA training, there were typically multiple relationships. That was my experience also - it was difficult to ensure clear separation of roles when there were so few people practising TA within a country - and similar limitations still exist in various parts of the world.

Cornell refers to six approaches to professional development defined by Hess (1980), to which he adds ongoing clinical supervision. The six include lectures and teaching, where there are unlikely to be issues if supervisees attend. Case reviews within an agency situation may be problematic because supervisees may risk exposure and judgement by peers and senior staff. Peer supervision works best when the participants are equal in role and status but can be limited by informality. Monitoring, such as on behalf of an agency or a professional association, involves a particular style of supervision which Cornell suggests is incompatible with a friendship or a therapeutic relationship, although he does not mention that TA supervisors all have a monitoring role that potentially clashes with the more developmental functions of the supervisory role.

The most relevant when we consider dual relationships within supervision are Cornell's addition of ongoing clinical supervision, and therapy. On supervision, Cornell writes "There is a strong quality of mentoring in these relationships, and a deep trust and mutual regard evolves between the supervisor and supervisee. In-depth personal supervision always evokes the atmosphere of a therapeutic relationship. However, the primary focus of attention for the supervisor is on the diagnosis, clinical understanding, adequate treatment, and protection of the supervisee's clients. The supervisee will likely experience feeling anxious, inadequate, confused, embarrassed, dependent, angry, or other unpleasant reactions.... The implications of dual relationships resulting from social or therapeutic activities need to be carefully considered and openly discussed. It is my view that any business or sexual relationship is completely incompatible with a supervisory relationship." (p. 28).

When commenting on therapy, Cornell writes that "It is not uncommon for supervisees to want to use the supervision as a vehicle for their personal therapy, centring it more on themselves and their own feelings and difficulties than on the problems and needs of their clients. The danger arises when the therapist's needs are not clearly identified as the overt focus of supervision and if a more client-centred supervisory structure is not also provided." (p. 29).
Bader (1994), writing in the same issue of the TAJ, pointed out that codes of ethics of non-TA associations (in the USA) were likely to prohibit some of the dual relationships that were typical within TA. She pointed out that many TA training programmes integrate therapy and supervision by the same trainer, and that she had herself had excellent training experiences in this format. For her, the "central questions should be: Is this relationship exploitative? Does it impair judgement? Focus is most meaningfully put on the question of exploitation, (italics in original) not on the question of duality." (p. 66). She went on to point out that most participants in TA training programs for advanced certification are informed consumers, who are usually held to the same standards as the trainers, and are therefore likely to be competent and knowledgeable enough to consider the risks involved and to make an informed choice.

McGrath (1994) suggested the application of moral principles for making decisions about boundaries. She quoted Thompson (1990) and Kitchener (1984) for the principles of "... nonmaleficence (do no harm), beneficence (promote good), fidelity (keep promises), justice (be fair), and autonomy (promote selfdetermination), together with the principle of universality (avoid special or self-serving situations)... (Haas \& Malouf 1989)". (p.8). She went on to add that Kitchener's (1988) role theory can be helpful through the consideration of areas: where discrepancy between roles increases, such as the incompatibility of the expectations between roles; where there is discrepancy between obligations associated with different roles; and where there is some differential in power and prestige between the parties involved.

Clarkson (1994) referred to increasing preoccupations with issues related to dual relationships, boundaries, and real or possible transgressions of these boundaries. She expressed concern that avoiding dual relationships had perhaps already gone too far, pointing out that psychotherapy involves multiple relationships relating to past, present, potential, historical and actual, and is therefore a much more complex field than ethical codes could ever hope to encompass. She also pointed out that many of the originators of psychoanalysis, analytic psychology and psychotherapy in general were involved in dual relationships with their patients that would nowadays be considered unwise if not unethical. She proposed that it is impossible for most psychotherapists to avoid all situations in which multiple roles might exist, that it is unfair to require trainees to achieve what most experienced psychotherapists know is impossible, and pointed out how at an annual professional gathering of those meant to be avoiding dual relationships, she could identify her current analyst, current supervisor, a current supervisee, the wife of a current client, the ex- 
wife of a colleague, several clients, a colleague on whose ethics board she had sat, etc. She added that if professional organisations were to truly prohibit dual relationships, then anyone still in therapy and/or supervision should not be organising conferences, publishing newsletters, or engaging in elections (or at least being voted for by some people).

Clarkson concluded by recommending that we develop "countertransferential awareness, methodological tools, and conceptual and moral facility in what I call "role fluency" as an alternative to rigidity. Role fluency refers to the competent ability to exercise appropriate, different roles in different situations with the same people. We should train and supervise with the realistic vicissitudes of the single-role therapeutic relationship in mind and not hold out an ideal state as normal or achievable. We need to equip ourselves and those we train to deal with rather than avoid real life and its impingement on the therapeutic frame. This is, of course, not to say we should not do everything in our power to avoid the misuse of dual-or multiple-role relationships." (p. 37)

Sills \& Mazzetti (2009) adopted a different view to Cornell and Clarkson. "We think that an important issue in training supervisors is to define a clear boundary between supervision and therapy. We are aware that supervision can have (and often does have) a therapeutic effect for the supervisee, but this is not the goal of supervision and should not be pursued by the supervisor ... In our practices, we support clearly differentiating between the supervision setting and the therapeutic one, including avoiding the dual relationship of acting as both supervisor and therapist - even in different settings - with the same person. This boundary clarity promotes professionalism and protects supervisees from the potential harm arising from a relationship that attempts to be therapeutic and yet also normative, educative, and evaluative." (p.305).

\section{The Fields of TA Application}

ITAA and EATA currently operate on the basis of the same Handbook, which contains descriptions of the four fields - psychotherapy, organisational, educational, counselling - in a way that clearly indicates that the requirements, in terms of standards and hours of professional application, training and supervision, are the same and only the practice is different.

It is interesting to note that Cornell, De Graaf, Newton \& Thunnissen (2016), in the book they have edited, include a Section 2 entitled Practice within which they refer to psychotherapy, counselling and coaching, management and organisational development, and learning and personal development - presumably these are meant to be how they view the psychotherapy, counselling, organisational and educational fields respectively.

Grégoire (1998) suggested we regard the boundaries between the fields as 'envelopes of coherence' so that we can avoid defining fields by contrasting them with each other. He uses another metaphor to explain this metaphor - the boundary of a tennis court is defined by the rules of tennis and not just by the physical existence; tennis and volleyball courts share a large common surface but are different in other respects; and the rules of tennis and volleyball are different so that you cannot play both of them at the same time.

Grégoire goes on to propose criteria for the envelope boundaries:

1. The goals - which must reflect the goal of the specific field, and exclude goals that belong under the other fields. He goes on to state that personal change can only be the primary goal of a therapy contract, and can only be a means or a consequence of the primary goals in terms of educational, organisational, counselling or training objectives. This seems an interesting and somewhat limiting view of how TA can be applied in different contexts.

2. The interventions - where the important characteristic is the protection provided; shortterm relationships give less protection than longterm; fostering a climate of self-revelation must be limited when co-workers are present.

3. Avoiding unnecessary dual relationships especially when a role involves a significant transference component, such as "... therapist, social worker, caretaker, superior, teacher, and so on." (p.318).

Grégoire concludes that there are techniques that should be used only in therapy, if they "would not fit with any nontherapeutic contract or relationship (first criterion) or where the kind of protection that one finds only in the therapeutic setting is required (second criterion), such as during interventions that reveal the Child ego state (age regression or the evocation of parental figures of a younger age; e.g., "Be 7 years (sic) and speak to your father") or cause abreaction..." (p.319).

He accepts that "profound personal change, including script change, takes place in supervision, education, counselling, and organisational development as well as in daily life. The supervisor, the teacher, or the change agent can validate and welcome what he or she sees as the beneficial result of his or her own behaviour, congratulate the client for the results achieved, and congratulate himself or herself on it." (p.320). It is worth noting at this point that Grégoire's TSTA accreditation is in psychotherapy. 


\section{Common Competencies}

Some years ago I (Hay, 2004b) proposed that the current division into four different fields of TA is unhelpful, based as it is on different groups having proposed specific sets of competencies. This is even more incongruous when we consider the research findings about common factors (Lambert \& Bergin 1994) and the dodo bird concept (Rosenweig 1936), which all point to the fact that the practitioner and the relationship with the client are highly significant and the particular theoretical backgrounds and specific approaches are of less importance.

Whilst preparing to obtain university accreditation for a TA programme, I combined the four sets of competencies into one set that would apply to any transactional analyst. For me, what is different is the type of evidence that can be seen - for example, 'available for intimate contact' might be evidenced by sharing in any field but may require that the way the practitioner ensures suitable opportunities occur will vary depending on the context - the appropriate sharing may be readily available during one-to-one contexts such as psychotherapy, counselling or coaching, but one-to-one encounters may need to be 'invited' within other contexts, such as during coffee breaks when running organisational interventions, during recess in classroom situations, through individual sessions with clients in family therapy, and sometimes even through individual sessions for clients in therapy groups.

I propose that CTA exams might be amended to run in a similar way to the exams for TSTA, in that everyone would take a basic examination that confirmed that they exhibit the necessary theoretical, professional, and ethical (TPE) characteristics to be regarded as a transactional analyst. This would be followed by shorter examinations where the candidate could present their evidence of working competently in a particular context, or in a series of such contexts. Having passed the original TPE exam, they could return as often as they wished to undertake further examinations to demonstrate additional contexts in which they can work competently.

I have also suggested that a start might be made by dividing the existing fields into some obviously different approaches. Hence, Counselling might be considered as separate applications of counselling versus coaching/mentoring. The Organisational field might be subdivided into providing training versus consulting my own lengthy organisational experience had involved consulting to an organisation, then providing supporting training events, followed by one-to-one coaching of participants to help them apply what they had learned during the training, in order for the organisation to get the benefit of the change that had been defined during the consultancy. The educational field already covers some clearly separate contexts, such as teaching children in schools, adult education in terms of life skills, parenting skills including with foster and adoptive parents, and work with migrants/refugees. When it came to psychotherapy, I hesitated at that time to suggest any divisions for a field in which I was not qualified; now that I am, much of my psychotherapy experience was with inmates in prisons, which also meant working with trauma and violence, whereas other psychotherapists have specialised in working with children where additional qualifications are required in the UK, with addicts, with families, with refugees, or with the victims of violence rather than with the perpetrators (although many perpetrators turned out to have been victims in their childhoods).

\section{Channels of communication}

To conclude, I present one final model that represents a bridge to contact: Hay's $(1995,2001,2009)$ AP $^{3}$ (named because the three axes are each labelled with $A$ and $P$ ). I routinely emphasise that my material is a simplification of Kahler's (1979a, 1979b) work and hence the framework should be used tentatively, although when people are very stressed their characteristics tend to become more pronounced and this means that our categorisation of someone is more likely to be correct. Hence this makes a useful framework, especially for the layperson, to enhance their chance of choosing the most appropriate channel when they initiate contact with someone new - and hence creating a bridge across boundaries.

As shown in Figure 33, I illustrate with a threedimensional shape of a cube, with three axes of which one is measured from top back corner to bottom front corner as this better represents the empirical evidence than it would if that dimension was simply drawn from front to back through the centre. I have amended and added to Kahler's original dimensions so that each began with the same letters to form a memory aid (in English):

- $\quad$ active - passive - do we initiate contact and move towards people and goals - or do we respond to contacts initiated by others and goals that 'emerge'?

- alone - people - do we prefer to be, or work, alone - or would we rather be functioning within a group of people, perhaps as the central figure?

- acceleration - patience - do we prefer to do things quickly, perhaps even with ever-increasing speed - or do we like to take our time, doing things slowly and carefully?

I go on summarise what I refer to as the $\mathrm{ABC}$ - Appearance, Behaviour and Channel (of communication) and the Preferences - which type of strokes best motivate, 


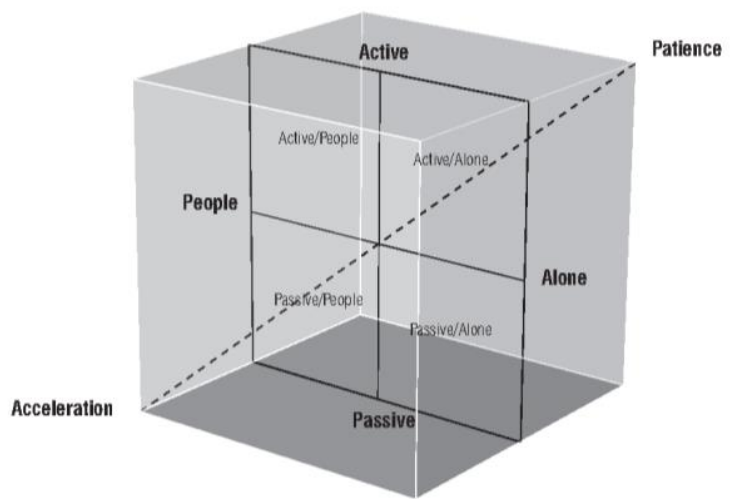

Figure 33: Perspective of the Assessing Cube AP3 (Hay, 2009 p. 191)

the likeliest working style/driver, and the preferred leadership style. Caution is needed about putting people into boxes; nevertheless I suggest that we can think in terms of 4.5 styles, as shown in Table 6 where the Acceleration dimension represents Hurry Up working style.

The more 'clues' we notice, the more confident we can be about our categorisation of someone; this will allow us to communicate in terms of the sequence of doors to therapy suggested by Ware (1983). These have been added to Table 6 . Talking about someone's behaviour will be a trap if we do this with someone who is Active/People or Active/Alone - these are likely to have Please People or Be Perfect drivers respectively and will therefore be at risk of hearing comments about their behaviour as indicating that they have failed to please of failed to be perfect. The trap for Passive/ People, who are likely to have Try Hard driver, is that they will engage in tricky thinking and seek to use logic to maintain their defences. The Passive/ Alone style, with Be Strong driver, are likely to struggle to be able to talk about their feelings.

\begin{tabular}{|l|l|}
\hline Active/People & Active/Alone \\
Appearance: colourful, jewellery & Appearance: business stress, smart, classical \\
Behaviour: initiate contact with group, talk about & $\begin{array}{l}\text { Behaviour: initiate contact with 1 or } 2 \text { people, talk } \\
\text { about work }\end{array}$ \\
person & Channel: Functional Adult - Functional Adult \\
Channel: A nurturing Parent-Natural Child & Strokes to motivate: about performance \\
Strokes to motivate: about the person & Working style: Be Perfect \\
Working style: Please People & Leadership style: Consulting \\
Leadership style: Caring & Doors to contact: thinking, feeling, behaviour \\
Doors to contact: feeling, thinking, behaviour & Passive/Alone \\
\hline Passive/People & Appearance: do not care about appearance \\
Appearance: unusual, idiosyncratic & Behaviour: wait to be spoken to, prefer to have a task \\
Behaviour: wait to be drawn into group, talk about & to do \\
hobbies (including work) & Channel: Controlling Parent - Adapted Child \\
Channel: Natural Child-Natural Child & Strokes to motivate: minimal politeness \\
Strokes to motivate: about play (such as hobbies or & Working style: Be Strong \\
exciting work projects) & Leadership style: Controlling \\
Working style: Try Hard & Doors to contact: behaviour, thinking, feeling \\
Leadership style: Connecting & \\
Doors to contact: behaviour, feeling, thinking & \\
\hline Acceleration & \\
Appearance: may be like any of the other styles & \\
Behaviour: moves and talks quickly & \\
Channel: may be any as long as fast & \\
Strokes to motivate: for productivity & \\
Working style: Hurry Up & \\
Leadership style: Concise & \\
Doors to contact: will depend on any similarities to & \\
the other styles & \\
\hline
\end{tabular}

Table 6: AP3 Summary - amended from Hay (2012 p. 192 and 193) 
On the other hand, asking a Please People about how they feel will seem natural to them, talking to a Be Perfect about their thinking will seem appropriate to them, interacting about their behaviour in terms of playfulness of hobbies or work will match the inclinations of a Try Hard, and telling them what behaviour you expect of them will be regarded as a reasonable interaction by someone with Be Strong. What I refer to as the half style, of acceleration, is someone with a Hurry Up style, who may well respond to any contact door, or channel of communication, provided that the speech is fast enough.

\section{Concluding Comments}

This paper began life as some notes in preparation for making a presentation at a conference, based on a topic that had been requested by the participants. At the same time, I noticed that boundaries and bridges were featured as topics for several conferences: boundaries was the topic for the 2017 TA World Conference organised by ITAA, EATA, FTAA and DGTA and this stimulated a special issue of the Transactional Analysis Journal; it was clinical boundaries for a recent Cumbrian TA Association event; as I was presenting my material, the South Asian Journal of Transactional Analysis published an issue on relationship boundaries; and a search via Google for bridges and boundaries generates many options.

As I pulled together the material, it became apparent to me that just about any TA concept can be applied to the notion of boundaries and bridges. What I have included here are the ones I am most familiar with - I have been teaching many of them to a variety of individual, group and organisational clients since the 1970s and to students of TA since the 1980s.

You will have seen that I went back and added material about power after this was prompted by a helpful reviewer - however, I have stopped after that because otherwise I suspect that I could go on adding more concepts ad infinitum. I welcome feedback from readers about any omissions or potential additions, and apologise to any authors whose material I have missed or misinterpreted.

Much of what I have written has already been included in handout workbooks I produce to accompany my international workshops and webinars; because IJTARP is open access, I encourage you to do likewise and share the information with others, whether you do that as the complete article or by extracting whichever parts you think will be most relevant for particular clients.

Rainer Maria Rilke (1875-1926) wrote:

I live my life in widening circles that reach out across the world.
Through physis (Berne, 1968) hopefully we can all widen our own and others' circles.

Julie Hay is a Teaching \& Supervising Transactional Analyst (Organisational, Psychotherapy, Educational) who is due to take her CTA (Counselling) oral examination in August 2018. She can be contacted on julie@juliehay.org

\section{References}

Allen, James \& Allen, Barbara (1991) Towards a Constructivist TA In Loria, Bruce (Ed) The Stamford papers: Selections from the 29th annual ITAA conference Madison, WI: Omnipress

Altorfer, Otto (1977) Authentic Courtesy and Personal Power: Two Aims of Emotional Job Fitness Transactional Analysis Journal 7:4 339-341

Bader, Ellyn (1994) Dual Relationships: Legal and Ethical Trends Transactional Analysis Journal 24:1 64-66

Bernard, Janine M \& Goodyear, Rodney K (1992) Fundamentals in clinical supervision Boston: Allyn \& Bacon

Berne, Eric (1961) Transactional Analysis in Psychotherapy New York: Grove Press

Berne, Eric (1963) The Structure and Dynamics of Organizations and Groups, New York: Grove Press

Berne, Eric (1964) Games People Play, New York: Grove Press

Berne, Eric (1966) Principles of Group Treatment, New York: Grove Press Inc

Berne, Eric (1968) A Layman's Guide to Psychiatry and Psychoanalysis $3^{\text {rd }}$ edition New York: Simon and Schuster (original work published in 1947 as The Mind in Action, New York: Simon and Schuster)

Berne, Eric. (1972) What Do You Say After You Say Hello? New York: Grove Press

Bion, Wilfred R (1968) Experiences in Groups and Other Papers London: Tavistock Publications (first published 1961 same publishers; page numbers in text relate to 1985 reprint)

Blakeney, R, N. \& Quick James (1976) Analysis of a Consortium of Social Service Organizations Transactional Analysis Journal 6:3 311-315

Buber, Martin (1923/1970) I and thou New York: Scribner (translation of original work published in German 1923)

Clark, Fred C. (1999) The Concept of Boundaries in Integrative Psychotherapy Transactional Analysis Journal 29:4 292-295

Clarke, Jean Illsley (1996) The Synergistic Use of Five Transactional Analysis Concepts by Educators Transactional Analysis Journal 26:3 214-219

Clarkson, Petrūska (1987) The Bystander Role Transactional Analysis Journal 17:3 82-87 
Clarkson, Petrūska (1988) Group Imago and the Stages of Group Development ITA News 20 4-16

Clarkson, Petrūska (1991) Group Imago and the Stages of Group Development Transactional Analysis Journal 21:1 3650

Clarkson, Petrūska (1993) Bystander Games Transactional Analysis Journal 23:3 158-172

Clarkson, Petrūska (1994) In Recognition of Dual Relationships Transactional Analysis Journal 24:1 32-38

Cornell, William (1994) Dual Relationships in Transactional Analysis: Training, Supervision, and Therapy Transactional Analysis Journal 24:1 21-30

Cornell, William, de Graaf, Anne, Newton, Trudi \& Thunnissen, Moniek (2016) Into TA: A Comprehensive Textbook on Transactional Analysis London: Karnac

Dostoevsky, Fyodor (1957) The Grand Inquisitor. The Brothers Karamazov. Book V, Chapter 5 New York: Signet Classics, published by The New American Library

English, Fanita (1969) Episcript and the "Hot Potato" Game Transactional Analysis Bulletin 8:32 77-82

English, Fanita (1979) Talk by Fanita English on Receiving the Eric Berne Memorial Scientific Award for the Concept of Rackets as Substitute Feelings Transactional Analysis Journal 9:290-297

Ernst Franklin (1971) The OK Corral; the grid for get-on-with Transactional Analysis Journal 1:4 231-240

Erskine, Richard (1993) Inquiry, Attunement, \& Involvement in the Psychotherapy of Dissociation Transactional Analysis Journal 23(4) 184-190

Evans, Mairi (1998) Supervision: A DevelopmentalRelational Approach Transactional Analysis Journal 28:4 288-298

Fox, Elliot (1975) Eric Berne's Theory of Organizations Transactional Analysis Journal 5:4 345-353

Grégoire, José (1998) Criteria for Defining the Boundaries of Transactional Analysis fields of application transactional analysis journal 28:4 311-320

Gurowitz, Edward M. (1975) Group Boundaries and Leadership Potency Transactional Analysis Journal 5:2 183185

Haas, Leonard J \& Malouf, John L. (1989) Keeping up the good work: A practitioner's guide to mental health ethics Sarasota FL: Professional Resource Exchange

Hall, Edward T (1966) The Hidden Dimension New York: Doubleday

Hargaden, Helena, (2013) Building Resilience: The Role of Firm Boundaries and the Third in Relational Group Therapy Transactional Analysis Journal 43:4 284-290

Hargaden, Helena \& Sills Charlotte (2002) Transactional Analysis - A Relational Perspective Hove: BrunnerRoutledge
Harris, Thomas (1969) I'm OK, You're OK New York: Harper \& Row

Hay, Julie (1995) Donkey Bridges for Developmental TA Watford: Sherwood Publishing

Hay, Julie (1996) Steps to Success INTAND Newsletter 4:3 Hay, Julie (2001) AP3: The Assessing Cube TA UK 59 1619

Hay, Julie (2004a) Sailship Success: a metaphor for leaders Training Journal, November 54-57

Hay, Julie (2004) Supervision Train the Trainer, 11

Hay, Julie (2004b) Unpublished Project Report to EATA

Hay, Julie (2007) Reflective Practice and Supervision for Coaches Maidenhead: Open University Press

Hay, Julie (2009) Transactional Analysis for Trainers $2^{\text {nd }}$ edition Hertford: Sherwood Publishing

Hay, Julie (2011a) Group Processes II: Leadership \& Power (unpublished workbook Hertford: Psychological Intelligence)

Hay, Julie (2011b) Transactional Analysis Introductory Course: Workbook Hertford: Sherwood

Hay, Julie (2012) Donkey Bridges for Developmental TA $2^{\text {nd }}$ edit Hertford: Sherwood Publishing

Hay, Julie (2016) Hay's Organisational Cone IDTA Newsletter 11: 4 19-20

Hay, Julie (2017) Sailship Success - an update IDTA Newsletter 12:4 6-10

Hess, Allen K (1980) Psychotherapy Supervision: Theory, Research and Practice. New York: Wiley

Hewitt, Gordon (1995) Cycles of Psychotherapy Transactional Analysis Journal 25:3 200-207

Holloway, William (1977) Transactional Analysis: An Integrative View in Barnes, G. (ed) Transactional Analysis after Eric Berne: Teachings and Practices of Three TA Schools, New York: Harper's College Press Chap 11 169221

Jacobs, Alan (1987) Autocratic Power Transactional Analysis Journal 17: 3 59-71

Jacobs, Alan (1991) Autocracy: Groups, Organizations, Nations, and Players Transactional Analysis Journal 21:4 199-206

James, John (1984) Grandparents and the Family Script Parade Transactional Analysis Journal 14:1 18-28

James, Muriel (1986) Diagnosis and Treatment of Ego State Boundary Problems Transactional Analysis Journal 16:3 188-196

James, Muriel \& Jongeward, Dorothy (1971) Born to Win Reading MA: Addison-Wesley Publishing Company, Inc Jung, Carl G. (1978) Man and his symbols London: Picador Kahler, Taibi (1979a) Managing with the Process Communication Model $2^{\text {nd }}$ edition Little Rock, AR: Human Development Publications 
Kahler, Taibi (1979b) Process Therapy in Brief $3^{\text {rd }}$ edition Little Rock, AR: Human Development Publications.

Kaplan, Kalman J. (1988) TILT: Teaching Individuals to Live Together Transactional Analysis Journal 18:3 220-230

Kaplan, Kalman J., Capace, Nancy K., Clyde, John Douglas (1984) A Bidimensional Distancing Approach to Transactional Analysis: A Suggested Revision of the OK Corral Transactional Analysis Journal 14:2 114-119

Kitchener, Karen S (1984) Intuition, critical evaluation, and ethical principles: The foundation for ethical decisions in counseling psychology The Counseling Psychologist 12 4355

Kitchener, Karen S (1988) Dual role relationships: What makes them so problematic? Journal of Counseling and Development 67 217-221

Krausz, Rosa (1986) Power and Leadership in Organisations Transactional Analysis Journal 16: 2 85-94

Lambert, Michael J \& Bergin, Allen E (1994) The effectiveness of psychotherapy. In S L Garfield \& A E Bergin (eds) Handbook of Psychotherapy and Behavior Change $4^{\text {th }}$ edit, 143-189 New York: Wiley

Lee, Adrienne (2014) The Development of a Process Group Transactional Analysis Journal 44:1 41-52

Lenhardt, Vincent (1991) personal communication presentation on Coaching \& Teambuilding at EATA/DGTA Conference July

Lenhardt, Vincent (2004) Coaching for Meaning: the culture and practice of coaching and team building Basingstoke, UK: Palgrave Macmillan

Levin, Pamela (1982) The Cycle of Development Transactional Analysis Journal 12:2 129-139

Lifshitz-Assaf Hila (2017) Dismantling Knowledge Boundaries at NASA: The Critical Role of Professional Identity in Open Innovation Online Appendix Administrative Science Quarterly

http://journals.sagepub.com/doi/suppl/10.1177/0001839217 747876 accessed $3^{\text {rd }}$ April 2018

Magee, James (1980) A Family Systems Context for LifeScript Analysis Transactional Analysis Journal 10:4 326-329

Mazzetti, Marco (2012) Phantoms in Organizations Transactional Analysis Journal 42:3 199-208

McGrath, Grace (1994) Ethics, Boundaries, and Contracts: Applying Moral Principles Transactional Analysis Journal 24:16-14

McQuillin, Jane \& Welford, Enid (2013) How many people are gathered here? Group work and family Transactional Analysis Journal 43:4 352-365

Noriega, Gloria (2009) On Receiving the 2008 Eric Berne Memorial Award for Mechanisms of Transgenerational Script Transmission Transactional Analysis Journal 39:1 813
Noriega Gayol, Gloria (1997) Diagnosis and Treatment of Ego State Boundary Problems: effects on self-esteem and quality of life Transactional Analysis Journal 27:4 236-240

Noriega Gayol, Gloria (2002) Construcción y Validación del Instrumento de Codependencia (ICOD) para Mujeres Mexicanas [Construction and Validation of the Codependency Instrument (ICOD) for Mexican Women] Salud Mental 25:2 38-48

Noriega Gayol, Gloria (2004) Codependence: A Transgenerational Script Transactional Analysis Journal 34:4 312-322

Novellino, Michele \& Moiso, Carlo, (1990) The Psychodynamic Approach to Transactional Analysis Transactional Analysis Journal 20:3 187-192

Peterson, Marilyn R (1992) At Personal Risk: Boundary Violations in Professional-Client Relationships New York: WW Norton \& Co

Polster, Erving \& Polster, Miriam (1974). Gestalt therapy integrated: Contours of theory and practice. New York: Random House

Rilke, Rainer (René) Maria (English version quotation by Anita Barrows and Joanna Macy) see https://www.britannica.com/biography/Rainer-Maria-Rilke accessed 10 March 2018

Roberts, Denton (1975) Treatment of Cultural Scripts Transactional Analysis Journal 5:1 29-35

Rogers, Carl (1990) The Carl Rogers reader ( $\mathrm{H}$. Kirschenbaum \& V. Land Henderson, Eds.). London: Constable.

Rosenweig, Saul (1936) Some implicit common factors in diverse methods in psychotherapy. American Journal of Orthopsychiatry, 6, 412-415

Schiff, Jacqui \& Contributors (1975), Cathexis Reader: Transactional Analysis Treatment of Psychosis, New York: Harper \& Row Publishers Inc

Searles, Harold F. (1955) The Informational Value of the Supervisor's Emotional Experiences Psychiatry Vol 18 pp. 135-146 (later reproduced in Collected Papers on Schizophrenia and Related Subjects, H. F. Searles, Karnac Books 1965)

Sills, Charlotte \& Mazzetti, Marco (2009) The Comparative Script System: A Tool for Developing Supervisors Transactional Analysis Journal 39:4 305-314

Sills, Charlotte \& Salters, Diane (1991) The comparative script system ITA News 31 1-15

Sironi, Françoise (2018) Clinical Geopolitical Psychology: A New Approach Adapted to Planetary Changes and Emerging Identities Transactional Analysis Journal 48:2, 8596

Stark, Martha (2000) Modes of Therapeutic Action Northvale $\mathrm{NJ}$ : Jason Aronson Inc. 
Steenbarger, Brett N (1992) Toward science-practice integration in brief counseling and therapy The Counseling Psychologist 20 403-450

Steiner, Claude (1987) The Seven Sources of Power: An Alternative to Authority Transactional Analysis Journal 17: 3 102-104

Stern, Daniel (1985) The Interpersonal World of the Infant: A view from psychoanalysis and developmental psychology New York: Basic books

Stoltenberg, Cal D \& Delworth, Ursula (1987) Supervising counselors and therapists San Francisco: Jossey-Bass

Stoltz, Sandra G. (1985) Beware of Boundary Issues Transactional Analysis Journal 15:1 37-41

Summers, Graeme \& Tudor, Keith (2000) Cocreative Transactional Analysis Transactional Analysis Journal 30:1 23-40

Symor, Nola Katherine (1983) Cycle de la dépendance, Actualités en analyse transactionnelle, vol. 7: 27
Thompson, Andrew R (1990) Guide to Ethical Practice in Psychotherapy New York: John Wiley

Tudor, Keith (2013) Group Imago and Group Development: Two Theoretical Additions and Ensuing Adjustments Transactional Analysis Journal 43:4 321-333

Van Poelje, Sari (1995) Development of Autocratic Systems Transactional Analysis Journal 25:3 265-270

Ware, Paul (1983) Personality Adaptations (Doors to Therapy) Transactional Analysis Journal 13:1 11-19

Welford, Enid (2014) Giving the Dead their Rightful Place: Grief Work with the Family System Transactional Analysis Journal 44:4 320-333

White, Tony (1997) Symbiosis and Attachment Hunger Transactional Analysis Journal 27:4 300-304

White, Tony (1998) Transference, Attachment, and the Transactional Symbiosis Transactional Analysis Journal 28:2 121-126 